\title{
Safe Operation of a Batch Reactor: Safe Storage of Organic Peroxides in Supply Vessels
}

\author{
Metske Steensma and K. Roel Westerterp* \\ Dedicated to Professor Dr. Kurt Dialer on the occasion of his 70 th birthday
}

In this study, we investigated the limits of safe operation for a cooled reactor, operated batchwise. As an example of a single-phase reaction, we studied the decomposition of $t$-butyl peroxypivalate, a well-known organic peroxide, undergoing self-heating at relatively low temperatures. If sufficiently diluted, it can be supplied to a polymerization process from large, cooled but unstirred vessels. We present a number of extensions to the existing homogeneous explosion theory, namely a practical definition of the critical condition, its calculation, and expressions for the available time before runaway in the case of a supercritical condition, taking into account the effects of natural convection inside the vessel and the reactant conversion. The extensions of the theory were confirmed by adiabatic and non-adiabatic runaway experiments on bench scale, and natural convection cooling experiments with liquids in various packages.

\section{Introduction}

Organic peroxides are widely used in the polymer industry as initiators of polymerization reactions. Their application requires skilful engineering to prevent violent decompositions. For safe storage of bulk quantities, these peroxides must be diluted with a phlegmatizing agent, usually an inert, organic solvent. This reduces the sometimes violent effect of a runaway reaction, caused by the self-heating properties of the organic peroxide. The dilution also reduces the decomposition rate of the peroxide, and the maximum temperature rise resulting from decomposition. The large cooled vessel for storage of a diluted peroxide can be regarded as a batch reactor in which all the reactants are present at the start of the batch. Although the operational goals of a batch reactor and of a cooling vessel for peroxides are different, namely a high and safe conversion of reactants for the batch reactor, as opposed to a low conversion without excessive cooling costs for a cooled storage vessel for peroxides, basically the same evaluation of the cooling system must be performed. Two possible outcomes of such an evaluation are observed in industrial practice: the cooled reactor is either subcritical, implying that there will be no runaway, or it is supercritical which means that the runaway cannot be arrested by the cooling system and will occur after a finite time interval. At critical conditions, this interval is infinitely long. The assessment whether such storage is subcritical or supercritical demands a thorough knowledge of the peroxide's thermal properties and heat transfer conditions.

The theoretical aspects of thermal explosions of unstable substances have been reviewed by Merzhanov and Abramov [1]. In the simplest model of a homogeneous explosion, the following assumptions are made:

* Dr. ir. M. Steensma, Akzo Chemicals, 7400 AA Deventer, The Netherlands, and Prof. dr. ir. K.R. Westerterp, University of Twente, Department of Chemical Engineering, P.O.Box 217, $7500 \mathrm{AE}$ Enschede, The Netherlands.
- A uniform temperature exists throughout the unstable substance.

- There is no consumption of the unstable substance, i.e. the reaction is of zero order with respect to the concentration of the unstable substance.

- The physical parameters relevant to the runaway process are constant.

The temperature variation of such an unstable substance, subjected to external cooling, can be derived from the heat balance, expressed as heat flow rate per unit volume $\left(\mathrm{W} / \mathrm{m}^{3}\right):{ }^{1)}$

$C_{\mathrm{p}} \varrho \frac{\mathrm{d} T}{\mathrm{~d} t}=\varrho Q_{\infty} \exp \left(-\frac{E}{R T}\right)-\frac{U A}{V}\left(T-T_{0}\right)$

The first term of Eq. (1) is the rate of heat absorption or accumulation by the test sample, the second term expresses the heat production rate due to self-heating of the substance while the third represents the heat exchange with the surroundings. Initial temperature $T_{0}$ of the unstable substance is assumed to be the same as that of the surroundings which, e.g. could be a hot room, a cold storage room, a cooling jacket or a refrigerator.

$Q_{\infty}$ is the heat production rate per unit mass at $T=\infty \mathrm{K}$ and zero conversion, known in the parlance of thermal explosion science as the heat production factor. Appendix 3 lists the equations for converting the parameters used in the thermal explosion science to their equivalents in the chemical reaction engineering science. For a generally applicable evaluation, Eq. (1) must be first converted into dimensionless form:

$$
\frac{\mathrm{d} \theta}{\mathrm{d} \tau}=\delta \exp \left(\frac{\theta}{1+\beta \theta}\right)-m \theta
$$

1) List of symbols at the end of the paper. 
where $\theta=\frac{E}{R T_{0}^{2}}\left(T-T_{0}\right)=\frac{\left(T-T_{0}\right)}{\beta T_{0}} \quad \begin{aligned} & \text { dimensionless } \\ & \text { temperature difference, }\end{aligned}$

$$
\begin{aligned}
& \beta=\frac{R T_{0}}{E} \\
& \tau=\frac{U t}{\varrho c_{\mathrm{p}} r}
\end{aligned}
$$

$\delta=\frac{E}{R T_{0}^{2}} \frac{\varrho r}{U} \exp \left(-\frac{E}{R T_{0}}\right) Q_{\infty}$

dimensionless heat production rate,

$m=r \frac{A}{V}$

geometric constant.

The geometric constant $m$ can adopt values between 1 and 3:

$m=1$ for a slab,

$m=2$ for an infinitely long cylinder,

$m=3$ for a sphere.

In order to find induction times to explosion, Eq. (2) must be integrated:

$\tau_{\text {expl }}=\int_{0}^{\theta_{\text {ad }}} \frac{\mathrm{d} \theta}{\delta \exp (\theta /(1+\beta \theta)-m \theta}$.

\section{Evaluation of the Simplest Model}

To find induction times, we simplify Eq. (3) by declaring that $\beta \theta$ is negligible, compared to unity. Further, the upper limit of the integral is taken as $\theta_{\mathrm{ad}}=\infty$. Only then is an analytical solution of Eq. (3) possible, as shown in appendix 1:

$t_{\text {expl }}=t_{\mathrm{ad}}\left[1+\sum_{i=1}^{\infty} \frac{i !}{(i+1)^{i+1} \mathrm{Se}^{i}}\right]$.

In Eq. (4a), two crucial parameters appear, namely the adiabatic induction time $t_{\mathrm{ad}}$ which is the time to explosion in the absence of cooling:

$t_{\mathrm{ad}}=\frac{R T_{0}^{2}}{E} \frac{c_{\mathrm{p}}}{Q_{\infty}} \exp \left(\frac{E}{R T_{0}}\right)$

and the Semenov number Se describing the ratio of heat production rate to cooling rate, according to:

$\mathrm{Se}=\left(\frac{E}{R T_{0}^{2}}\right) \varrho\left(\frac{V Q_{\infty}}{U A}\right) \exp \left(-E / R T_{0}\right)=\delta / m$

In Eq. (4a), a convergence limit emerges, namely $\mathrm{Se}_{\mathrm{cr}}=1 / \mathrm{e}^{\prime}$, explained in appendix 1. Fig. 1, a plot of Eq. (4a), reveals two asymptotes, namely:

$\frac{t_{\text {expl }}}{t_{\mathrm{ad}}}=\infty$ for $\mathrm{Se}=\mathrm{Se}_{\mathrm{cr}}$

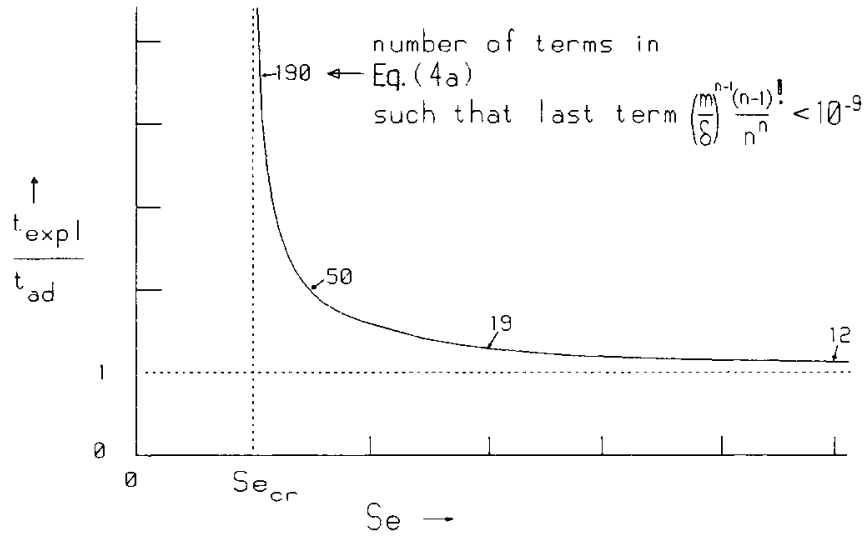

Fig. 1. Generalized representation of induction time under supercritical conditions.

and

$\frac{t_{\text {expl }}}{t_{\text {ad }}}=1$ for $\mathrm{Se}=\infty$.

For Se $<\mathrm{Se}_{\mathrm{cr}}$, the conditions are no longer supercritical and a runaway will not occur. Analysis of the solution of Eq. (4a) by several approximative correlations led to one particularly accurate expression:

$\frac{t_{\mathrm{expl}}}{t_{\mathrm{ad}}}=\left[1+\frac{A}{\mathrm{Se}_{\mathrm{Se}} \mathrm{er}_{\mathrm{cr}}-1}\right]^{B}$.

The parameters $A$ and $B$ in Eq. (5) are constants, as yet without physical meaning. $A$ and $B$ can be derived from a somewhat unusual linear regression analysis, aimed at obtaining a slope of exactly -1 for a function of the type

$\log \left(y^{1 / B}-1\right)=\log A+\log (x-1)$

by varying $B$, even though this does not produce the highest possible regression coefficient. Nevertheless, the regression coefficient remains very close to unity. Such an analysis of the exact solution of Eq. (4a) yields the following approximative correlation.

$\frac{t_{\text {expl }}}{t_{\mathrm{ad}}}=\left[1+\frac{1.1334}{\mathrm{Se} / \mathrm{Se}_{\mathrm{cr}}-1}\right]^{0.6038}$

with a regression coefficient $r=0.999984$ for $1.1<\mathrm{Se} / \mathrm{Se}_{\mathrm{cr}}$ $<15$. There is only a small deviation between the exact and approximative curves, very close to the critical condition $\mathrm{Se}=$ $\mathrm{Se}_{\mathrm{cr}}$, see Fig. 2.

Correlations of the type of Eq. (5) will be used whenever explosion times must be correlated with the distance from the critical condition. It should be noted that, even in a laboratory experiment, the critical condition, which is a function of kinetic and heat transfer parameters, is very sensitive to small measurement errors, as shown in Table 1.

Adiabatic induction times of self-heating substances as measured in a laboratory set-up, usually a Dewar vessel kept 


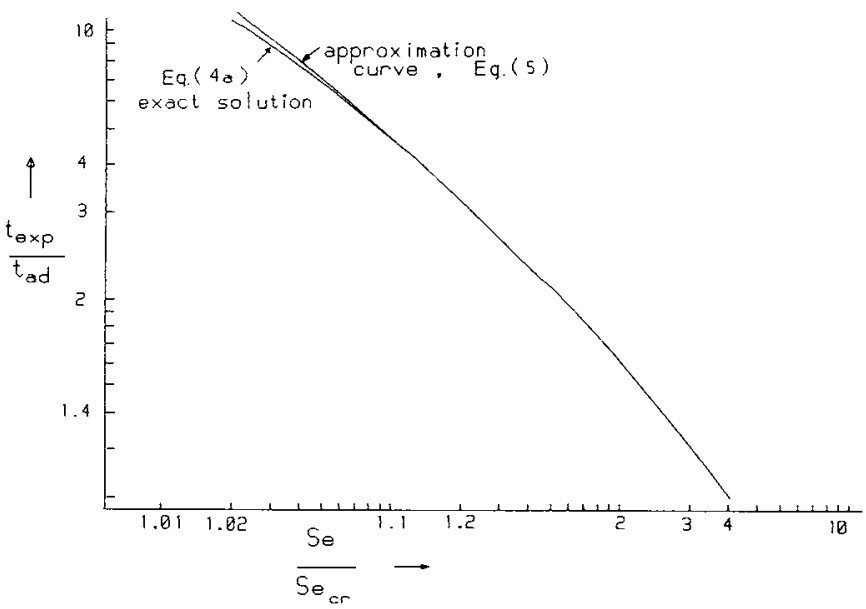

Fig. 2. Exact solution of Eq. (4a) and the approximative function, Eq. (5), with $A=1.134$ and $B=0.6038$.

Table 1. Accuracy of critical condition measurement.

\begin{tabular}{cc}
$\begin{array}{c}\text { Temperature accuracy } \\
{[\mathrm{K}]}\end{array}$ & $\begin{array}{c}\text { Error in the Semenov number } \\
{[\%]}\end{array}$ \\
\pm 0.25 & 5 \\
\pm 0.50 & 10 \\
\pm 1.00 & 20 \\
\hline
\end{tabular}

in an oven, maintained at the same temperature as the sample, are also subject to inaccuracies when a small but constant temperature gradient exists between the oven and the sample, e.g. due to calibration errors. This will be discussed later.

\section{Definitions of "Explosion" and "Critical Conditions"}

The two states, i.e. of explosion and of critical condition in the numerical solution of Eqs. (1) or (2) are interrelated: if a state is judged as just critical, then the induction time to explosion, corresponding to that state, must be just infinite. In such a situation, the temperature ranges between runaway and stabilization, as seen in Fig. 3. For a better indication of the difference between supercritical and subcritical conditions, we have taken the conversion of the self-heating substance into account in Fig. 3. This resulted in a temperature-time curve asymptotically approaching a horizontal for one value of $\delta$.

There is a maximum stable difference $\theta_{\mathrm{cr}}$ between the ambient temperature and that of the unstable substance. $\theta_{\mathrm{cr}}$ is referred to as the "maximum pre-explosive temperature rise" or, more accurately, "maximum subcritical temperature excess" (Merzhanov and Abramov, [1]).

For a zero order runaway reaction, and under the limiting assumption of $\beta \theta=0$, solution of Eq. (2) for $\mathrm{d} \theta / \mathrm{d} \tau=0$ and $\mathrm{d}^{2} \theta / \mathrm{d} \tau^{2}=0$, which are the limiting conditions for stable temperature behaviour, yields:

$\theta_{\mathrm{cr}}=1$ or $\Delta T_{\mathrm{cr}}=R T_{0}^{2} / E$, based upon $\delta_{\mathrm{cr}}=m / \mathrm{e}$ if $\beta \theta \approx 0$.

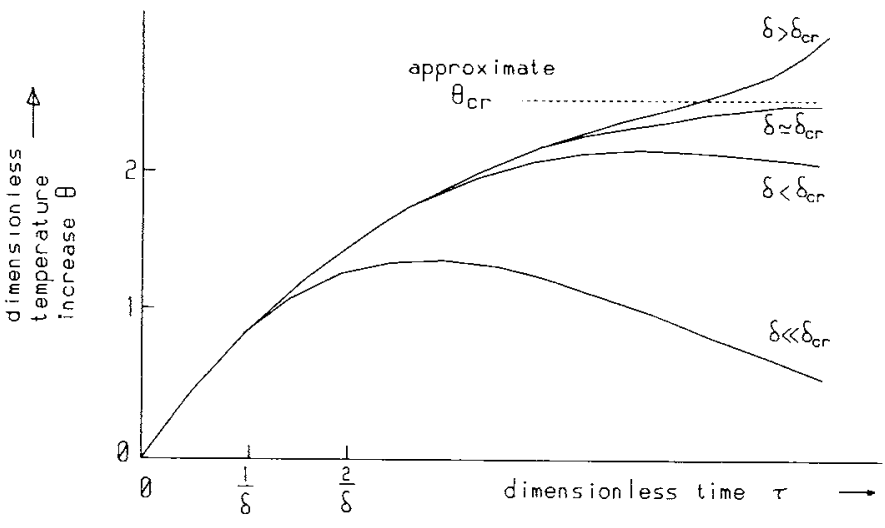

Fig. 3. Indicative temperature profiles as functions of time, for $\delta \approx \delta_{\mathrm{cr}}$. Conversion of reactant taken into account.

For a reaction with infinitely large reaction heat, but with a realistic value of $\beta$, we will soon find that $\theta_{c r}$ is still very close to unity. This means that the maximum stable difference between ambient temperature and that of an undiluted organic peroxide is between 6 and $9{ }^{\circ} \mathrm{C}$ because, as a rule, $12000<$ $E / R<18000 \mathrm{~K}$ and $273<T_{\mathrm{o}, \mathrm{cr}}<353 \mathrm{~K}$ for organic peroxides. If $\delta$ is taken as slightly above $\delta_{\mathrm{cr}}$, the temperature will rise steadily and between $\theta=5$ and 6 really start to run away. In appendix 2 , we give an approximate time-temperature profile near the runaway point.

The definition of explosion is essentially arbitrary although, for a highly exothermic system, it will hardly be ambiguous. Bowes [2] considers that "an explosion, like an elephant, is easier to recognize than to define, and hence we may press our stopwatch as soon as we are convinced that we have seen one. The only necessary requirement is consistency".

The problem now is to find a reasonable value for $\theta_{\text {expl }}$. For diluted unstable substances, the adiabatic temperature rise $\Delta T_{\text {ad }}$ is rather low and the effect of concentration on the rate of reaction must be taken into account. We find that the maximum stable $\theta_{\mathrm{cr}}$, albeit very difficult to establish, increases gradually at small $\Delta T_{\mathrm{ad}}$, and the jump in temperature at $\theta=5$, under supercritical conditions, becomes less pronounced. Values for $\theta_{\mathrm{cr}}$, as used by several investigators, range from $\theta=2$ to $\theta=$ 5 (Bowes, [2]). Own calculations point to values around $\theta_{\mathrm{cr}}=$ 5 for diluted organic peroxides with concentrations of approximately $40 \%$, for which $\Delta T_{\text {ad }}$ is 250 to $300 \mathrm{~K}$. This definition obviates the numerical difficulties of finding accurately the real explosion point, which corresponds to $\theta_{\mathrm{ad}}=25-200$. For a highly exothermic system given by e.g. $\theta_{\mathrm{ad}}=200$, it hardly matters whether $\theta=5$ or above is adopted as the explosion point. Taking a much lower value of $\theta$ as the explosion point, for instance $\theta=1.5$, would be against our finding that less exothermic systems may "recover" from such a temperature deviation, but not from a $\theta=5$ temperature deviation (see appendix 2). Hence, for consistency reasons, we have used the following definitions:

$\theta=5$ signifies explosion: the induction time to explosion is the time from $\theta=0$ to $\theta=5$. 
$\delta_{\mathrm{cr}}$ is the value of $\delta$ at which the temperature profile no longer stabilizes. The maximum subcritical temperature excess is assumed to be less than or equal to $\theta_{\mathrm{cr}}=5$. Only very diluted systems reach $\theta_{\mathrm{cr}}$-values slightly above 5 and subsequently still undergo temperature stabilization.

The above definitions lead to a small reduction of the adiabatic induction time as given by Eq. (4b), which assumes $\theta=\infty$ as the explosion point:

$\tau_{\text {expl }} \delta=\int_{0}^{5} \frac{\mathrm{d} \theta}{\exp (\theta)}=0.993$

The above expression contains $\tau_{\text {expl }} \delta$ rather than $\tau_{\text {expl }}$ because, according to Eq. (4b):

$\tau_{\text {expl }} \delta=\frac{t_{\text {expl }}}{\frac{R T_{0}^{2}}{E} \frac{c_{\mathrm{p}}}{Q_{\infty}} \exp \left(\frac{E}{R T_{0}}\right)}=-\frac{t_{\text {expl }}}{t_{\mathrm{ad}}}$.

Adiabatic or strongly supercritical conditions yield an explosion at $\tau_{\text {expl }} \delta \approx 1$ but, under conditions close to criticality, $\tau_{\text {expl }} \delta$ can attain much higher values. Transposition of the expression for $\tau_{\text {expl }} \delta$ yields:

$t_{\mathrm{ad}}=0.993 \frac{R T_{\mathrm{o}}^{2}}{E} \frac{C_{\mathrm{p}}}{Q_{\infty}} \exp \left(\frac{E}{R T_{\mathrm{o}}}\right)$.

The time interval from $\theta=\theta_{\text {expl }}$ to $\theta=\infty$ can normally be neglected.

\section{The $\beta$-Correction}

\subsection{Influence of $\beta$ on Maximum Subcritical Temperature Excess and Critical Value of $\delta$}

The effect of cooling, on the one hand, and self-heating of the unstable substance, on the other hand, as described by Eq. (1), can be illustrated in a Semenov diagram (Merzhanov and Abramov, [1]), see Fig. 4. Fig. 4 represents a critical balance

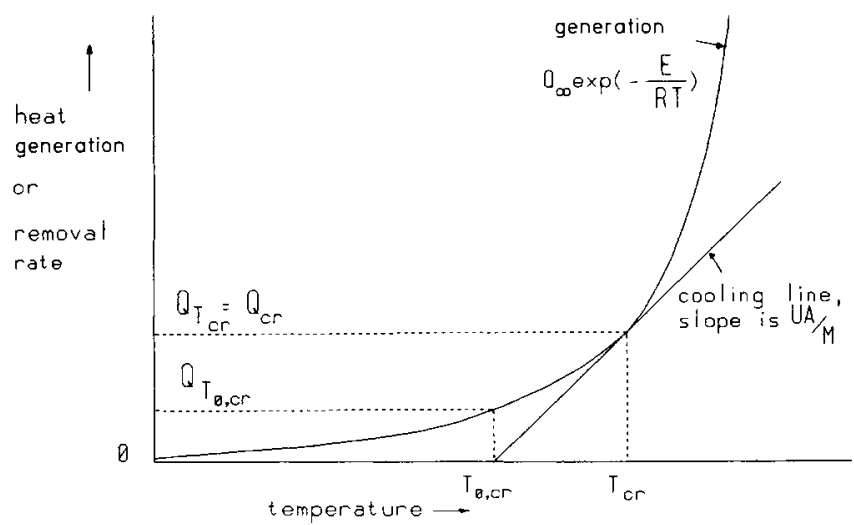

Fig. 4. Critical cooling condition represented in a Semenov diagram. Simplest case. between cooling and self-heating. The heat balance at the critical temperature $T_{\mathrm{cr}}$ of the self-heating substance reads:

$M\left(\frac{\mathrm{d} Q}{\mathrm{~d} T}\right)_{T_{c r}}=U A$

in which $M$ is the mass of the above substance and $Q$ the heat production rate per unit mass, according to $Q_{\mathrm{T}}=Q_{\infty} \times$ $\times \exp \times(-E / R T)$

Evaluation of the heat balance at $T_{\text {cr }}$ yields:

$M Q_{\infty} \exp \left(-\frac{E}{R T_{\mathrm{cr}}}\right) \frac{E}{R T_{\mathrm{cr}}^{2}}=U A=\frac{M Q_{\mathrm{cr}}}{T_{\mathrm{cr}}-T_{\mathrm{o}, \mathrm{cr}}}$

$T_{0, \mathrm{cr}}$ is the well-known Self-Accelerating Decomposition Temperature SADT, i.e. the lowest ambient temperature at which a self-heating compound will undergo a runaway reaction. Transposition yields:

$T_{\mathrm{cr}}-T_{0, \mathrm{cr}}=\Delta T_{\mathrm{cr}}=\frac{R T_{\mathrm{cr}}^{2}}{E}$ or $\theta_{\mathrm{cr}}=\frac{T_{\mathrm{cr}}^{2}}{T_{\mathrm{o}, \mathrm{cr}}^{2}}$

We see that $\theta_{\mathrm{cr}}$ attains values above unity if $\beta$ is no longer zero. Fig. 5 shows that, at two temperatures (1) and (2), the net heat production rate of the system becomes zero, since the selfheating effect is balanced by cooling. The first intersection point represents a stable operating condition while the second one corresponds to a state of high starting temperatures whereby the reaction system will either run away at a marginally higher temperature or move to the first, stable point. In the critical case, these two points merge. In the supercritical case, these two intersection points cease to exist.

An analysis of such criticality data, carried out for organic peroxides, with the following typical properties (Akzo Chemicals, brochure, [3]):

critical ambient temperatures ranging from 0 to $70^{\circ} \mathrm{C}$, activation energy $E / R$ between 12.000 and $18.000 \mathrm{~K}$,

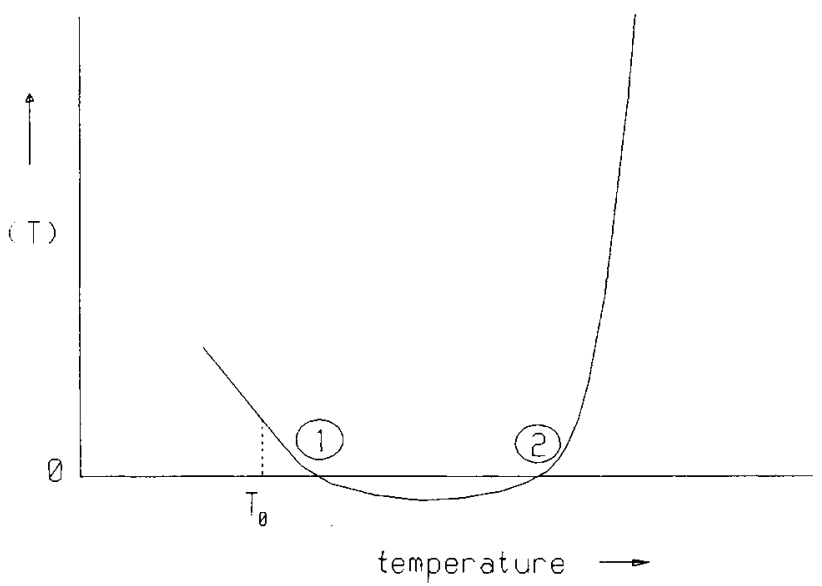

Fig. 5. Representation of net heat production rate of a self-heating substance under cooling $f(T)=Q_{\infty} \exp (-E / R T)-U A / M\left(T-T_{0}\right)$. 
heat production rate from 0.01 to $0.1 \mathrm{~W} / \mathrm{kg}$ at the critical ambient temperature (these values represent good estimates for bulk storage and packages of 25 to $50 \mathrm{~kg}$ respectively), yields a linear relationship between $T_{0, \mathrm{cr}}^{2}$ and $T_{\mathrm{cr}}^{2}$ according to:

$T_{\mathrm{cr}}^{2} / T_{\mathrm{o}, \mathrm{cr}}^{2}=\theta_{\mathrm{cr}}=1+2.1 \beta$

with a regression coefficient of $r=0.9994 . \theta_{\text {сг }}$ is independent of the heat production factor $Q_{\infty}$ and the applied cooling intensity $U A / M$.

A purely mathematical approach is described by Gray and Lee (in Tipper (ed.), [4]). They solve Eq. (7), regarded as a quadratic equation in $T_{\mathrm{cr}}$, directly and find for the intersection point:

$T_{\mathrm{cr}}=\frac{E}{2 R}\left[1-\left(1-\frac{4 R T_{\mathrm{o} . \mathrm{cr}}}{E}\right)^{1 / 2}\right]$.

The square root can be expanded into a binomial series as follows:

$\theta_{\mathrm{cr}}=1+2 \beta+5 \beta^{2}+14 \beta^{3}+\ldots$

This is somewhat similar to Eq. (8), derived indirectly for a more limited range of $\beta$ and $T_{\mathrm{cr}}$. Substitution of the stability criterion $\mathrm{d} \theta / \mathrm{d} \tau=0$ and Eq. (8) into Eq. (2) results in the correlation $\delta_{\mathrm{cr}}=(m / \mathrm{e}) f(\beta)$.

Numerical evaluation yields an accurate expression for $f(\beta)$, namely the $\beta$-correction to the original critical value of $\delta$ :

$\delta_{\mathrm{cr}}=\frac{m}{\mathrm{e}} \exp \left(\frac{\beta}{1-\beta}\right)$

The correction term $\exp (\beta /(1-\beta))$ in Eq. (10) comes close to the correction term $(1+\beta)$ proposed by Parks (in Merzhanov and Abramov [1]).

\section{2 $\beta$-Correction for Adiabatic Induction Time}

By taking $\delta=1$ and $m=0$ for the simulation of adiabatic conditions, and $\theta=5$ as the explosion criterion, we find after regression analysis of the numerical data:

$\tau_{\text {expl }} \delta=0.993(1+1.83 \beta)$ or: $t_{\text {expl }}=(1+1.83 \beta) t_{\mathrm{ad}}$

where $t_{\mathrm{ad}}$ is given by Eq. (6). The $\beta$-correction of the adiabatic induction time is obviously $(1+1.83 \beta)$, close to the term $(1$ $+2 \beta$ ), proposed by Barzykin (in: Merzhanov and Abramov, [1]).

\subsection{Induction Times for Supercritical Conditions $\delta>\delta_{\mathrm{cr}}$}

Eq. (2) can be solved numerically for $\delta>\delta_{\text {cr }}$, to calculate explosion times under supercritical conditions. $\beta$-values range from 0 to 0.075 . For organic peroxides, $\beta$ does not exceed 0.03 . The results are plotted in Fig. 6 .

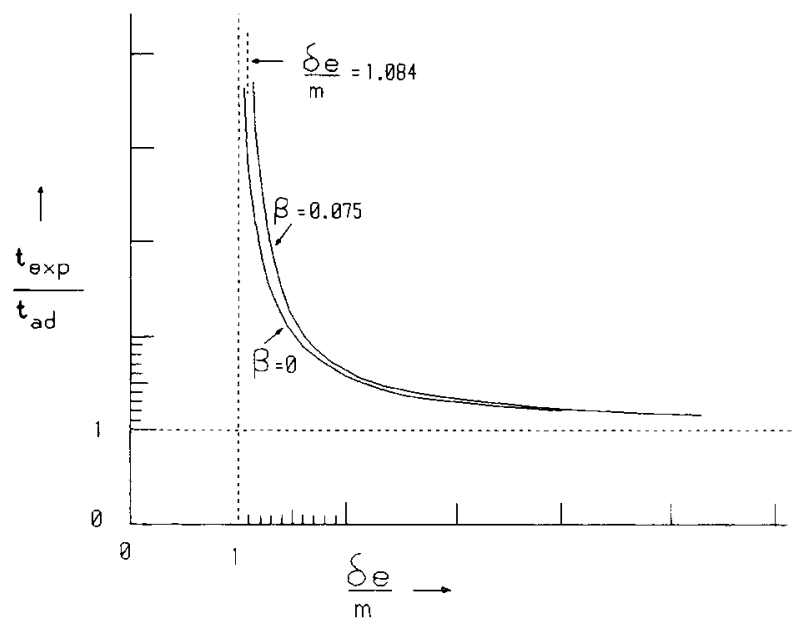

Fig. 6. Explosion times under supercritical conditions. Influence of activation energy.

No correction is applied for conversion.

A correlation between explosion time and critical $\delta$-value in the form of Eq. (5) yields the following expression, with $r \approx$ 0.9999 for the given range of $\beta$-values:

$\frac{t_{\text {expl }}}{t_{\mathrm{ad}}}=\left[1+\frac{1.17}{\mathrm{Se} / \mathrm{Se}_{\mathrm{cr}}-1}\right]^{0.59}$

In the application of this approximative equation, $\delta_{\mathrm{cr}}$ and $t_{\mathrm{ad}}$ must be calculated using Eqs (10) and (11), respectively.

\section{The Conversion Correction}

\subsection{Incorporation of Conversion in the Model}

Until now, we neglected the role of conversion which automatically reduces the heat production rate, extends the time to explosion, and increases the critical Semenov number.

The adiabatic temperature rise for organic peroxides, diluted to $40 \%$ with an inert phlegmatizer, is between 250 and $300 \mathrm{~K}$. This implies that, at the $\theta=5$ point, corresponding to a temperature increase of 30 to $45 \mathrm{~K}$, the conversion is at least 10 to $20 \%$. At near-critical conditions, the conversion is considerably higher because the decomposing peroxide loses heat for a relatively long time without undergoing a runaway reaction. The result of conversion $\zeta$ for an $n^{\text {th }}$-order reaction is a fall in the heat production rate by a factor of $(1-\zeta)^{n}$. Conversion $\zeta$ can be derived from the temperature rise since the onset of the runaway reaction and the heat dissipated to the surroundings:

$\zeta=\frac{c_{\mathrm{p}}\left(T-T_{0}\right)}{\Delta H_{\mathrm{r}, \mathrm{w}}}+\frac{\int_{0}^{t_{\mathrm{expl}}} U A\left(T-T_{0}\right) \mathrm{d} t}{\Delta H_{\mathrm{r}, \mathrm{w}} \varrho r A / m}$.

The heat of reaction $\Delta H_{\mathrm{r}, \mathrm{w}}$ (for thermal explosion phenomena always based on mass, $\mathrm{J} / \mathrm{kg}$ ) is equal to the heat of decomposi- 
tion in the case of exclusive self-heating of organic peroxides, and can be expressed in terms of the adiabatic temperature rise $\Delta T_{\text {ad }}$ :

$\Delta T_{\mathrm{ad}}=\frac{\Delta H_{\mathrm{r} \cdot \mathrm{w}}}{c_{\mathrm{p}}}$

By invoking the definitions of the dimensionless parameters $\beta$, $\theta, m$ and $\tau$, we can now rearrange Eq. (12) into a dimensionless form:

$\zeta=\gamma_{\mathrm{H}}\left(\theta+m \int_{0}^{\tau_{\text {expl }}} \theta \mathrm{d} \tau\right)$

where $\gamma_{\mathrm{H}}=\frac{\beta T_{0}}{\Delta T_{\mathrm{ad}}}=\frac{c_{\mathrm{p}}}{\Delta H_{\mathrm{r}, \mathrm{w}}} \frac{R T_{0}^{2}}{E} . \begin{aligned} & \text { parameter for reactant } \\ & \text { consumption. }\end{aligned}$

The dimensionless group $\gamma_{\mathrm{H}}$ is the usual parameter, describing the influence of conversion (Gray, Sherrington, [5]). Corrections arising from this influence are referred to as the $\gamma_{\mathrm{H}}$-corrections.

Eq. (14) is solved simultaneously with the modified Eq. (2) and reads as follows for the decomposition of a diluted organic peroxide, with assumed first order kinetics:

$\frac{\mathrm{d} \theta}{\mathrm{d} \tau}=(1-\zeta) \delta \exp \left(\frac{\theta}{1+\beta \theta}\right)-m \theta$

\subsection{Influence of Conversion on Critical $\delta$-Value}

Analysis of the critical $\delta$-values as functions of $\Delta T_{\mathrm{ad}}$ above 250 $\mathrm{K}$ and $\beta$ in the range between 0 and 0.03 indicates that the influence of the parameter $\gamma_{\mathbf{H}}$ is the most significant while the effect of $\beta$ as a separate parameter for activation energy is very small. The following expression results from a regression analysis:

$\delta_{\mathrm{cr}} / \delta_{0}=1+4.33 \gamma_{\mathbf{H}}^{0.75}$

in which $\delta_{0}=(m / \mathrm{e}) \exp (\beta /(1-\beta))$ is the reference state.

The influence of reactant consumption is also tested for a second order runaway reaction, e.g. a batch reaction with components in stoichiometric quantities, and this yields the following expression:

$\delta_{\mathrm{cr}} / \delta_{0}=1+4.29\left(2 \gamma_{\mathrm{H}}\right)^{0.75}$

with accuracy given by $r=0.9996$. We now postulate, in accordance with Frank-Kamenetskii (Merzhanov and Abramov, [1]) for heterogeneous self-heating processes, that under conditions of reactant consumption $\delta_{\mathrm{cr}}$ can be expressed as follows:

$\delta_{\mathrm{cr}} / \delta_{0}=1+4.3\left(n \gamma_{\mathrm{H}}\right)^{0.75}$

where $n$ is the order of reaction.

\subsection{The Influence of Reactant Consumption on Adiabatic Induction Time}

The adiabatic induction time is also slightly influenced by conversion. The adiabatic case can be represented by a simplified equation obtained by combining Eqs (2) and (4) and adopting $m=0$ and $\delta=1$.

$\frac{\mathrm{d} \theta}{\mathrm{d} \tau}=\exp \left(\frac{\theta}{1+\beta \theta}\right)\left(1-\gamma_{\mathbf{H}} \theta\right)$

Analysis of the data from solution of Eq. (17) yields the equation for $t_{\mathrm{ad}}$ as:

$t_{\mathrm{ad}}=0.993 \frac{R T_{0}^{2}}{E} \frac{c_{\mathrm{p}}}{Q_{\infty}} \exp \left(\frac{E}{R T_{0}^{2}}\right)(1+1.83 \beta)\left(1+1.62 \gamma_{\mathrm{H}}^{1.1}\right)$.

\subsection{Influence of Reactant Consumption on Explosion Time}

Having derived the correlations for $\delta_{\mathrm{cr}}$ and $t_{\mathrm{ad}}$, we can now deduce the influence of reactant consumption on explosion time under supercritical conditions, and set the results in the mathematical form of Eq. (5). Fig. 7 gives the data for explosion times under supercritical conditions for three selected values of $\Delta T_{\mathrm{ad}}$, namely 250,600 and $1200 \mathrm{~K}$. The approximative correlations of the form of Eq. (5) are again valid with an excellent fit.

The values $A=1.6$ and $B=0.4$ in Eq. (5) are adequate for all realistic conditions in storage of diluted organic peroxides.

\section{Natural Convection Correction}

\subsection{Incorporation of Natural Convection Effects}

It follows from the theory of natural (free) convection that the heat transfer coefficient for a flow of heat from a body to a stagnant medium depends slightly on the temperature difference,

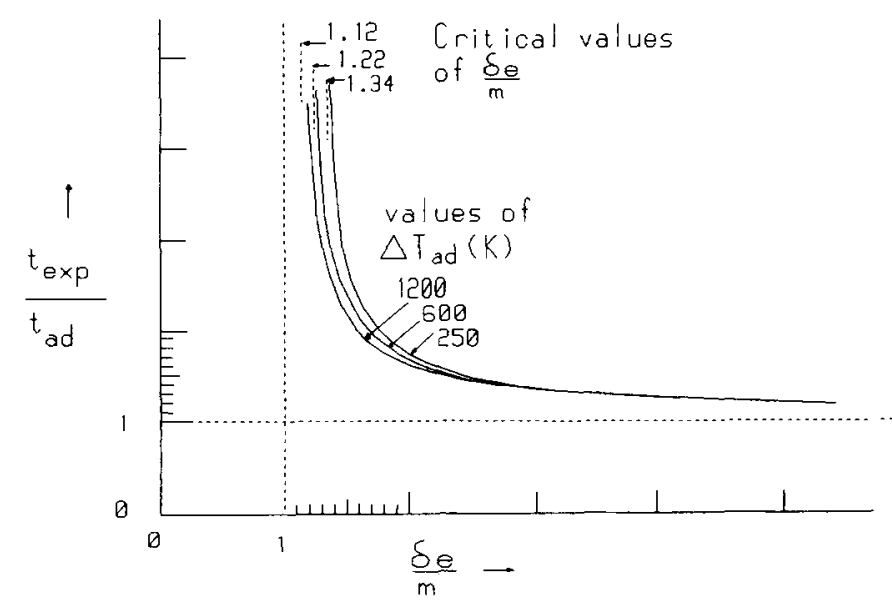

Fig. 7. Explosion times under supercritical conditions. Correction for conversion is applied. $T_{0}=293 \mathrm{~K}$ and $\beta=0.025$. 
making the heat flow rate proportional to $\Delta T^{1.25}$ to 1.33 (Beek and Muttzall, [6]). Also other parameters relevant to the runaway process are slightly dependent on temperature or temperature difference.

- The specific heat capacity is a function of temperature, especially for alcohols, which are common decomposition products of most organic peroxides (Perry, [7]);

- Some solvents used for phlegmatization of peroxides, notably phthalic esters, have viscosities strongly dependent on temperature. As a result, the heat transfer coefficient is also considerably affected by temperature, with a significant influence on criticality (Moise, Pritchard, [8]).

- The radiative heat transfer coefficient is nearly proportional to $\Delta T^{3}$ (Beek and Muttzall, [6]).

- We assumed a constant ambient temperature at a relatively high external heat transfer coefficient. This can be achieved by a cooling jacket but not by the relatively gentle air motion, such as in cold storage. As a result, the external heat transfer coefficient may depend slightly on the temperature difference between the self-heating sample and the surroundings.

It is seen that the cooling curves for cases of natural convection, or other temperature effects which are similarly described, can be easily mistaken for Newtonian cooling curves based on a perfect proportionality between the heat flow rate and the temperature gradient.

Cooling curves are routinely recorded for measurement of thermal half-life, $t_{1 / 2}$, of the small $0.5 \mathrm{dm}^{3}$ Dewar vessels filled with $0.4 \mathrm{dm}^{3}$ self-heating material for the SADT-test. It is impractical to perform this standard test in the usual maximum package size of $50 \mathrm{~kg}$ and a simulation test in a Dewar vessel with the same thermal characteristics since the package size of $50 \mathrm{~kg}$ is universally accepted. The UNO handbook (UNO, [11]) prescribes that Dewar vessels must be used for this simulation test with a $t_{1 / 2}$ of not less than $5 \mathrm{~h}$, using $400 \mathrm{ml}$ of dimethyl phthalate as the calibration substance. The exact procedure for the calculation of $t_{1 / 2}$ is not prescribed but, evidently, warm dimethyl phthalate is poured into the Dewar vessel, which is then placed in a thermostat. The temperature is recorded and the time, at which the original temperature difference is halved, is taken as $t_{1 / 2}$. Occasionally, hot tap water is used instead of dimethyl phthalate and the required $t_{1 / 2}$ is corrected to compensate for higher density and specific heat capacity of water.

Cooling of a hot mass in a constant temperature environment can be approximated by:

$\left(C_{\mathrm{w}}+M c_{\mathrm{p}}\right) \frac{\mathrm{d} T}{\mathrm{~d} t}=-\left[(U A)^{\prime}\left(T-T_{\text {constant }}\right)^{q-1}\right]\left(T-T_{\text {constant }}\right)$

where $q=1$ represents Newton's cooling law. $C_{\mathrm{w}}$ is the heat capacity of the vessel in $\mathrm{J} / \mathrm{K}$ and $(U A)=(U A)^{\prime}$ for $\Delta T=1{ }^{\circ} \mathrm{C}$.

Integration of Eq. (19) from $T_{0}$ to $T$ and 0 to $t$ yields:

$\frac{1}{1-q}\left|\left(T-T_{\text {constant }}\right)^{1-q}-\left(T_{\mathrm{o}}-T_{\text {constant }}\right)^{1-q}\right|=-\frac{(U A)^{\prime}}{C_{\mathrm{w}}+M c_{\mathrm{p}}} t$.
Hence, regression analysis of the cooling curve in the form $y$ $=$ const $t$ should yield a straight line. In the analysis, $q$ can be varied till the maximum value of the regression coefficient is obtained. If $q=1$, the usual logarithmic equation results:

$\ln \left|\frac{\left(T-T_{\text {constant }}\right)}{\left(T_{\mathrm{o}}-T_{\text {constant }}\right)}\right|=-\frac{(U A)^{\prime}}{C_{\mathrm{w}}+M c_{\mathrm{p}}} t$.

Computed data of a non-Newtonian cooling curve, on which we will demonstrate various regression analysis techniques, are given in Table 2.

Analysis of data in Table 2 according to the transformed Eq. (20) for $q=1.3333 \ldots$ naturally yields the value $(U A)^{\prime} /\left(C_{\mathrm{w}}+\right.$ $\left.M_{\mathrm{cp}}\right)=0.03 \mathrm{~h}^{-1}{ }^{\circ} \mathrm{C}^{-1 / 3}$ and the regression coefficient is 1 . However, the problem is that other values of $q$ also yield regression coefficients very close to unity. For example, $q=$ 1.3 results in $r=0.999874$, while $q=1.4$ yields $r=0.9995$. The small deviations of the regression line from a straight line, if $q$ is not optimal, are only perceptible in an accurate plot of the transformed data. Even for $q=1$, the Newtonian case, using the logarithmic transformation Eq. (21), seemingly straight lines are obtained but their slopes appear to depend on the respective temperature range, see Table 3 . The value of $t_{1 / 2}$ for a Newtonian-type cooling curve can be derived from Eq. (21) as $t_{1 / 2}=\ln 2 /$ slope of the regression line.

The analysis in Table 3 shows that the value of $t_{1 / 2}$, derived from an actual cooling curve, may increase rapidly if a small initial temperature difference is set. This is not only inconvenient for the calibration of Dewar vessels for the SADT-tests but, what is more important, it raises the question as to how important are the natural convection effects at near-critical condi-

Table 2. Calculated data for cooling of a non-Newtonian liquid. $T_{0}=$ $60{ }^{\circ} \mathrm{C}, T_{\text {const }}=20{ }^{\circ} \mathrm{C}, q=1.3333 \ldots,(U A)^{\prime} /\left(C_{\mathrm{w}}+M c_{\mathrm{p}}\right)=$ $0.0300 \mathrm{~h}^{-1{ }^{\circ} \mathrm{C}^{-1 / 3}}$

\begin{tabular}{rc}
$\begin{array}{c}\text { Time } \\
{[\mathrm{h}]}\end{array}$ & $\begin{array}{c}\text { Temperature } \\
{\left[{ }^{\circ} \mathrm{C}\right]}\end{array}$ \\
\hline 0 & 60.00 \\
0.5 & 58.02 \\
1.0 & 56.16 \\
1.5 & 54.40 \\
2.0 & 52.80 \\
2.5 & 51.27 \\
3.0 & 49.84 \\
4.0 & 47.23 \\
5.0 & 44.91 \\
6.0 & 42.85 \\
8.0 & 39.36 \\
10.0 & 36.55 \\
12.0 & 34.26 \\
14.0 & 32.37 \\
16.0 & 30.80 \\
18.0 & 29.49 \\
20.0 & 28.33 \\
25.0 & 26.23 \\
30.0 & 24.79 \\
40.0 & 23.00 \\
50.0 & 22.00 \\
60.0 & 21.40 \\
$\infty$ & 20.00 \\
&
\end{tabular}


Table 3. Values of $(U A)^{\prime} /\left(M c_{\mathrm{p}}+C_{\mathrm{w}}\right)$ and $t_{1 / 2}$ determined from the nonNewtonian cooling curve, given by data in Table 2, by dividing it into temperature intervals with assumed Newtonian behaviour.

\begin{tabular}{cccc}
\hline $\begin{array}{c}\text { Temperature } \\
\text { range of regres- } \\
\text { sion analysis } \\
{\left[{ }^{\circ} \mathrm{C}\right]}\end{array}$ & $\begin{array}{c}\text { Best fit value } \\
(U A)^{\prime} /\left(M c_{\mathbf{p}}+\right. \\
\left.C_{\mathrm{w}}\right) \\
{\left[\mathrm{h}^{-1}\right]}\end{array}$ & $\begin{array}{c}\text { Apparent value } \\
\text { of } t_{1 / 2}\end{array}$ & $\begin{array}{c}\text { Regression } \\
\text { coefficient } r\end{array}$ \\
\hline $60 \ldots 55$ & 0.100 & 6.93 & \\
$60 \ldots 53$ & 0.0993 & 6.98 & 0.9999 \\
$60 \ldots 47$ & 0.0963 & 7.20 & 0.9999 \\
$60 \ldots 40$ & 0.0904 & 7.67 & 0.9999 \\
$60 \ldots 30$ & 0.0798 & 8.69 & 0.9994 \\
$47 \ldots 30$ & 0.075 & 9.24 & 0.9991 \\
$34 \ldots 25$ & 0.0614 & 11.29 & 0.9991 \\
$29 \ldots 25$ & 0.0587 & 11.81 & 0.9995 \\
\hline
\end{tabular}

tions with small temperature gradients. One approach of taking natural convection and other temperature effects into account in the criticality calculations is to assume the following dimensionless correlation:

$U / c_{\mathrm{p}}=\left(U / c_{\mathrm{p}}\right)_{0} \theta^{q-1}$

in which $\left(U / c_{\mathrm{p}}\right)_{0}$ is the value of $U / c_{\mathrm{p}}$ at $\theta=1$. As shown, the exponent $q$ can be derived from a relatively simple cooling or heating experiment. The established theory about the influence of free convection on self-heating deals with the increase of $\delta_{\mathrm{cr}}$ in oxidative self-heating of particulate solids or powders (Bowes, [2]). Merzhanov and Shtessel [9] studied the onset of motion in thin layers between 0.5 and $4 \mathrm{~cm}$, at rather low temperature differences of 0.1 to $0.5{ }^{\circ} \mathrm{C}$. Vasseur and Robillard [10] studied numerically the steady state natural convection patterns of a fluid in a rectangular cavity with uniformly decreasing wall temperature. They concluded that free convection occurs from a Grashof number Gr of approx. $10^{3}$ for a Prandtl number $\operatorname{Pr}$ of 73 to $\mathrm{Gr} \approx 10^{4}$ at $\mathrm{Pr} \approx 0.73$. Further, a transition to a different flow regime occurs at $\mathrm{Gr} \approx 80000$. The common element in all these studies is the relationship between the heat transfer coefficient and the temperature difference, applied in Eq. (22). The effect of free convection on $\delta_{\mathrm{cr}}$ in large scale, cooled storage tanks with self-heating materials has not yet been established. Substitution of Eq. (22) into the basic Eqs (2) and (14) yields, after a few rearrangements:

$\frac{\mathrm{d} \theta}{\mathrm{d} \tau}=\delta \exp \left(\frac{\theta}{1+\beta \theta}\right)(1-\zeta)-m \theta^{q}$

and

$\zeta=\gamma_{\mathrm{H}}\left(\theta+m \int_{0}^{T} \theta^{q} \mathrm{~d} \tau\right)$

The definition of $\delta$ is now based on $U_{0}$ rather than on $U$.

\subsection{Influence of Natural Convection on $\delta_{\mathrm{cr}}$}

The influence of natural convection, characterized by exponent $q$, on the critical $\delta$-value is shown in Fig. 8. The reference

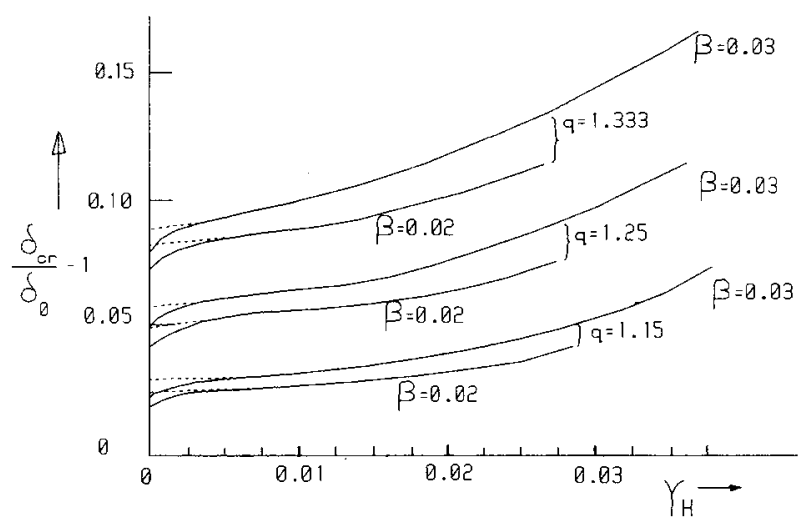

Fig. 8. Dependence of criticality on natural convection exponent $q$ and conversion correction, for two dimensionless reciprocal activation energies $\beta$.

value $\delta_{0}$ corresponds to $q=1$, given by Eq. (15), which already includes the $\beta$ - and $\gamma_{\mathrm{H}}$-corrections.

By smoothing the first part of the curves in Fig. 8 for $\gamma_{H}<$ 0.005 along the broken lines, justified since $\gamma_{\mathbf{H}}$ is always larger than 0.005 , the following accurate expression can be derived for the critical value of $\delta$ :

$\frac{\delta_{\mathrm{cr}}}{\delta_{0}}=1+\left(q^{4}-1\right)\left(0.024+0.6 \beta+25 \gamma_{\mathrm{H}}^{2}\right)$

where $\delta_{0}$ corresponds to the conditions at which we apply the natural convection correction, namely $\delta_{0}=(m / \mathrm{e}) \exp (\beta /(1-\beta)) \times$ $\times\left(1+4.33\left(n \gamma_{\mathbf{H}}\right)^{0.75}\right)$. The result is a rather complex equation but it shows the separate effects of $\beta, \gamma_{\mathbf{H}}$, the order of reaction $n$ and the natural convection exponent $q$.

\subsection{Influence of Natural Convection on Adiabatic Induction Time}

The definition of the adiabatic induction time implies no cooling at all. Hence, the correlation for $t_{\mathrm{ad}}$, as given by Eq. (18), must be employed.

\subsection{Induction Times for Supercritical Conditions}

Calculations show that, for every specific condition given by a set of parameter values $\beta, \gamma_{\mathbf{H}}$ and $q$, a correlation of the type of Eq. (5) can be found with an excellent fit for the best choice of the adjustable constants $A$ and $B$. This is exemplified in Table 4 for two extreme conditions for bulk storage of diluted organic peroxides. Table 4 also gives the accuracy of approximation of the critical $\delta$-value by Eqs (24) and (15), compared to the calculated values.

Thus far, a number of combinations $(A, B)$ were found by linear regression analysis and it is therefore useful to check whether there is a significant correlation between them.

Analysis of the data from this study yields $A=2.243-$ $1.804 B$, with $r=0.9882$ and a standard deviation of 0.015 , 
Table 4. Criticality data for bulk storage of diluted organic peroxides under natural convection cooling. First order decomposition kinetics assumed.

\begin{tabular}{|c|c|c|c|c|c|c|c|c|}
\hline Combination & $\Delta T_{\mathrm{ad}}$ & $\beta$ & $q$ & exact & $\begin{array}{l}\text { Er } \\
\text { Eq. }(24)+ \\
\text { Eq. }(15)\end{array}$ & $A$ & $\begin{array}{l}\text { Regression } \\
\text { analysis } \\
B\end{array}$ & $r$ \\
\hline 1 & 250 & 0.03 & 1.333 & 1.614 & 1.613 & 1.6889 & 0.2886 & 0.99912 \\
\hline 2 & 400 & 0.02 & 1.25 & 1.276 & 1.279 & 1.5371 & 0.3713 & 0.99955 \\
\hline
\end{tabular}

see Fig. 9. Increasing the order of the regression polynomial does not improve the accuracy of the correlation between $A$ and $B$. Given the accuracy obtainable by using the two parameters $A$ and $B$ in Eq. (5) and similar equations, and the not understood physico-chemical meaning of parameters $A$ and $B$, it is not justified to rearrange Eq. (5) and similar equations to ones with only one adjustable parameter.

\section{The Generalized “ $\tau-\delta$ ”-Diagram}

Fig. 10 is a generalized diagram showing explosion times as a function of the distance to the critical condition. Results of adiabatic and supercritical calculations are usually represented in a " $\tau-\delta$ "-diagram as the dimensionless induction time $\tau_{\operatorname{expl}}$ plotted against the dimensionless heat production rate $\delta$ at the initial temperature (van de Putte and Groothuizen, [12]). At critical values of $\delta_{\mathrm{cr}}$, which are, depending on geometry, approximately unity, vertical asymptotes are obtained because, at $\delta<\delta_{\mathrm{cr}}$, an explosion cannot develop.

In our generalized approach, the $x$ - and $y$-coordinates of the diagram are slightly adapted so that $\delta$ is replaced by $\mathrm{Se} / \mathrm{Se}$ cr. This reduces the number of asymptotes to only one, namely at $\mathrm{Se}=\mathrm{Se}_{\mathrm{cr}}$. In addition, $t_{\mathrm{ad}}$ is not taken as a fixed constant, given by Eq. (4b), but corrected for the effects of $\beta, \gamma_{\mathbf{H}}$ and the order of reaction $n$. The $x$-coordinate is $x=\mathrm{Se} / \mathrm{Se}_{\mathrm{cr}}$ instead of $\delta$ and the $y$-coordinate is $y=\left(t_{\text {expl }} / t_{\mathrm{ad}}\right)\left(\mathrm{Se} / \mathrm{Se} \mathrm{cr}_{\mathrm{cr}}\right)$ instead of $\left(t_{\text {expl }} / t_{\mathrm{ad}}\right) \delta$.

The adiabatic line is obtained as a straight line in a log-log plot as $t_{\mathrm{expl}}=t_{\mathrm{ad}}$, which yields $x y=1$.

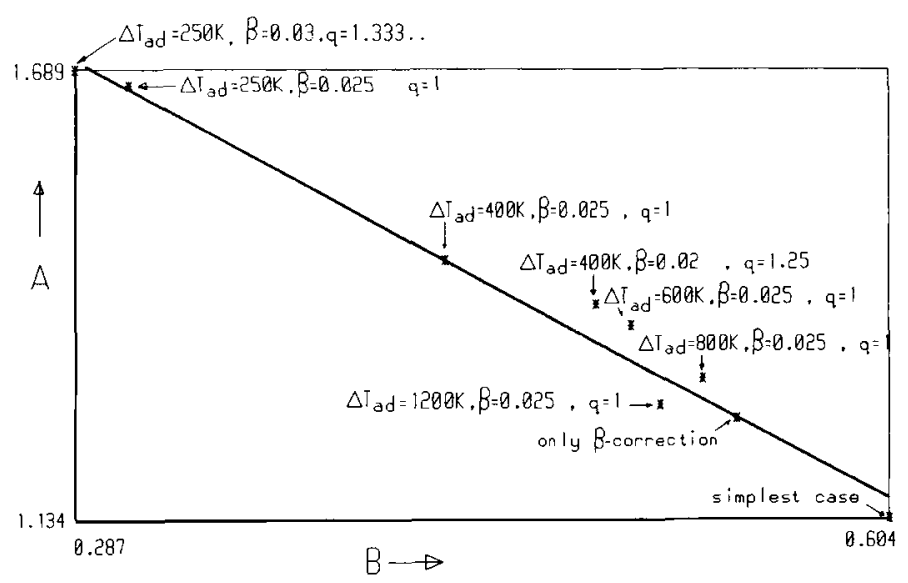

Fig. 9. Linear regression analysis of a number of combinations $(A, B)$ used in correlations similar to Eq. (5).
It is seen from Fig. 10 that, if $\mathrm{Se} / \mathrm{Se}_{\mathrm{cr}}>5$, the conditions are practically adiabatic or, in other words, the time interval to the actual runaway is scarcely increased by cooling. The broken line in Fig. 10, referred to as "no corrections", represents the exact solution of Eq. (4a), describing the simplest case with $\beta$ $=0$, reaction order zero, and $q=1.00$. The line "all corrections" applies to conditions of the highest dilution, $\Delta T_{\mathrm{ad}}=250$ $\mathrm{K}$, the highest conceivable value of $\beta$, at least for organic peroxides, $\beta=0.03$, the largest exponent in the natural convection correction $q=1.333$ and a reaction order $n=1$. Intermediate conditions can be represented by a line between these two extremes.

\section{Experiments}

\subsection{Adiabatic Runaway Experiment}

A $500 \mathrm{ml}$ Dewar flask is filled with $400 \mathrm{ml}$ of peroxide, closed by a stopper with only one small hole for thermocouple leads and placed in a small oven without forced heat circulation. The PID-controller for the oven is calibrated with pure isododecane, which does not undergo self-heating. The oven temperature should remain constant in the entire range planned for the experiment if there is no additional heating. The PIDcontroller is set in such a way that the oven provides a little ex-

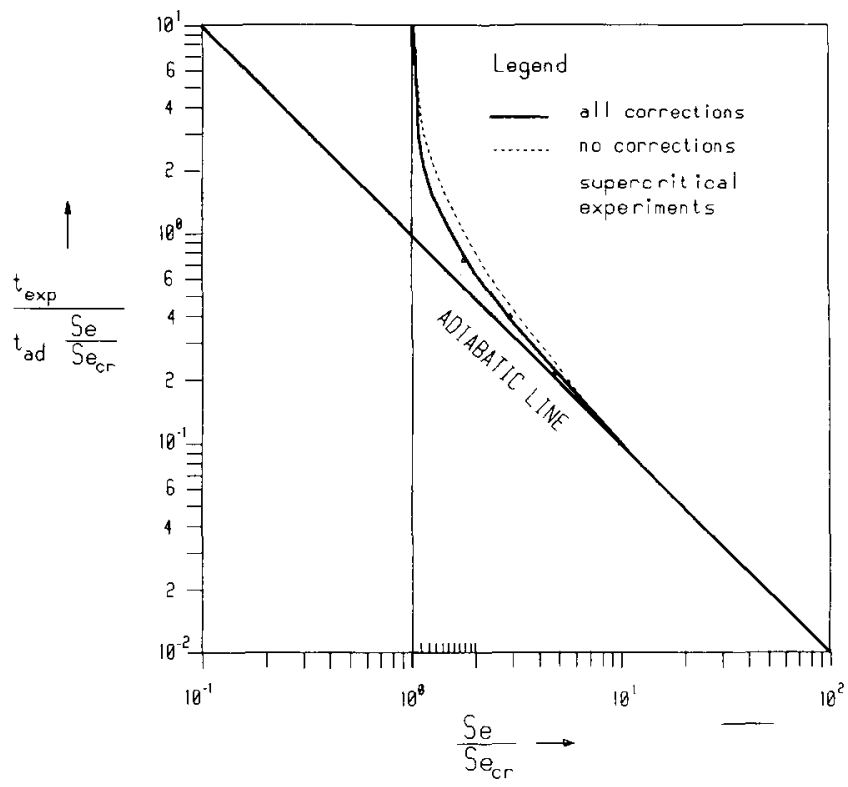

Fig. 10. Generalized $\tau-\delta$ diagram, adapted to contain only one vertical asymptote. 
tra heat for the Dewar vessel, to compensate for its heat capacity, should self-heating become perceptible. The set-up is placed in a concrete cell and remote-controlled, for the sake of personnel safety.

Fig. 11 presents a time profile of temperature. Using the data points, an Arrhenius plot of $\ln \left(Q_{0}\right)$, i.e. heat evolution per unit mass at zero conversion vs $1 / T$ was obtained by a smoothing differentiation procedure (Douglas, Aviakan, in Perry, [7]). Differentiation is necessary since $Q[\mathrm{~W} / \mathrm{kg}]=\left(1 / c_{\mathrm{p}}\right) \mathrm{d} T / \mathrm{d} t$.

The evaluation procedure takes conversion into account:

$Q_{0}=\frac{Q}{1-\zeta} \quad$ where $\zeta=\frac{\Delta T_{\text {since } t=0}}{\Delta T_{\text {ad }}}$.

The adiabatic temperature rise can be calculated from the reported data as $\Delta T_{\text {ad }}=269 \mathrm{~K}$ and the specific heat capacity of the liquid is $2176 \mathrm{~J} / \mathrm{kg}^{\circ} \mathrm{C}$. The regression analysis of the data of the Arrhenius plot yields $Q_{\infty}=1.18 \times 10^{19} \mathrm{~W} / \mathrm{kg}$ and $E / R$ $=13753 \mathrm{~K}$. Hordijk et al. [13] mention different values of $Q_{\infty}$ and $E / R$ for this diluted peroxide but the value of the parameter $Q_{\infty} \exp \left(-E / R T_{0}\right)$ is almost the same. The thermal properties given in [13] are valid for an extended temperature range. Generally, self-heating properties can be described more accurately for a narrow temperature range. The adiabatic induction time to $\theta=5$ at an initial temperature of $295.1 \mathrm{~K}$ can now be calculated with the aid of Eq. (18) as $59.7 \mathrm{~h}$, in good agreement with the experimental value of $60.5 \mathrm{~h}$. Calculation of the adiabatic induction time from the data of Hordijk et al. [13] yields $72.9 \mathrm{~h}$.

\subsection{Influence of Deviations from Truly Adiabatic Measurement}

Another problem in adiabatic measurements is the influence of small, constant temperature differences between the oven and sample. This influence will be assessed for the same $40 \%$ by mass organic peroxide, using a variant of Eq. (1) without the conversion correction of adiabatic induction time, which is known to be small:

$\frac{\mathrm{d} T}{\mathrm{~d} t}=\frac{Q_{\infty}}{c_{\mathrm{p}}} \exp \left(-\frac{E}{R T}\right)-\frac{U A}{\varrho c_{\mathrm{p}} V}\left(\Delta T_{\text {sample-oven }}\right)$

where $\Delta T_{\text {sample-oven }}$ is constant during a run.

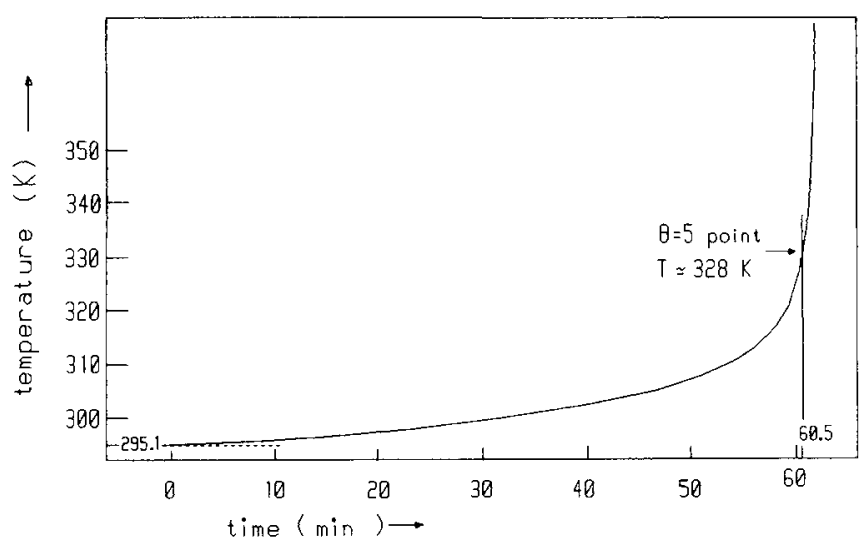

Fig. 11. Adiabatic runaway experiment with $t$-butyl peroxypivalate, 40 mass- $\%$ in isododecane.

The direct numerical integration of Eq. (25) yields the runaway time, based on the $\theta=5$ criterion, of $58.2 \mathrm{~h}$ in the ideal case of the temperature difference being zero. For the execution of the adiabatic test, the investigator chooses a reasonably small sample size, in order to reduce the effects of a possible runaway reaction. For a truly adiabatic measurement, the result must be independent of sample size. Apart from the $\Delta T_{\text {sample-oven }}$, the dominant factor is the parameter $U A /\left(\varrho c_{\mathrm{p}} V\right)$, characterizing the Dewar vessel. Table 5 gives the results of explosion time calculations for a number of cases.

The characteristics of the Dewar vessels in Table 5 are based on the following assumptions:

(1) is a $1.2 \mathrm{dm}^{3}$ Dewar vessel containing $1 \mathrm{~kg}$ organic substance with $c_{\mathrm{p}}=2500 \mathrm{~J} / \mathrm{kg} \mathrm{K}$, according to the official UNO-test.

(2) is a $0.5 \mathrm{dm}^{3}$ Dewar vessel containing $0.4 \mathrm{~kg}$ organic substance with $c_{\mathrm{p}}=2500 \mathrm{~J} / \mathrm{kg} \mathrm{K}$, i.e. the accepted SADTsimulation test.

(3) is a $0.1 \mathrm{dm}^{3}$ Dewar vessel containing $0.05 \mathrm{~kg}$ organic substance with $c_{\mathrm{p}}=2000 \mathrm{~J} / \mathrm{kg} \mathrm{K}$, in a mini-adiabatic test.

It is striking that a small heat exchange with the surroundings can have such a dramatic effect on the experimental adiabatic induction time. Therefore, resistance thermometers with 0.001 $\mathrm{K}$ accuracy in combination with a good control system must be applied.

Table 5. Calculated explosion times (in hours) in case of small deviations from true adiabatic conditions.

Set 1: original parameters and $Q_{\infty}=1.18 \times 10^{19} \mathrm{~W} / \mathrm{kg}$.

Set 2: the same $E / R, c_{\mathrm{p}}$ etc. but $Q_{\infty}=1.18 \times 10^{20} \mathrm{~W} / \mathrm{kg}$, resulting in 10 times shorter induction time to explosion.

\begin{tabular}{|c|c|c|c|c|c|c|}
\hline \multirow{3}{*}{$\begin{array}{l}\Delta T_{\text {sample - oven }} \\
{[\mathrm{K}]}\end{array}$} & \multicolumn{6}{|c|}{ Characterization of Dewar vessel $U A\left(\varrho c_{\mathrm{p}} V\right)$ in $\left[\mathrm{s}^{-1}\right]$} \\
\hline & \multicolumn{3}{|c|}{ Set 1} & \multicolumn{3}{|c|}{ Set 2} \\
\hline & $\begin{array}{l}1.33 \times 10^{-5} \\
\text { (1) }\end{array}$ & $\begin{array}{l}2.7 \times 10^{-5} \\
(2)\end{array}$ & $\begin{array}{l}8 \times 10^{-5} \\
\text { (3) }\end{array}$ & $\begin{array}{l}1.33 \times 10^{-5} \\
\text { (1) }\end{array}$ & $\begin{array}{l}2.7 \times 10^{-5} \\
(2)\end{array}$ & $\begin{array}{l}8 \times 10^{-5} \\
\text { (3) }\end{array}$ \\
\hline+0.50 & 52.8 & 48.4 & 37.5 & 5.76 & 5.70 & 5.48 \\
\hline+0.25 & 55.3 & 52.7 & 45.0 & 5.79 & 5.76 & 5.64 \\
\hline 0 & 58.2 & 58.2 & 58.2 & 5.82 & 5.82 & 5.82 \\
\hline-0.25 & 61.5 & 65.4 & 92.6 & 5.85 & 5.88 & 6.01 \\
\hline-0.50 & 65.4 & 76.0 & subcrit & 5.88 & 5.95 & 6.22 \\
\hline
\end{tabular}




\subsection{Supercritical Experiments in a Dewar Vessel}

\subsubsection{Characterization of a Dewar Vessel and Contents}

A Dewar flask and its contents undergo a certain heat loss, quantifiable by the two parameters in Eq. (22), i.e. the natural convection exponent $q$ and $(U A)^{\prime} /\left(M c_{\mathrm{p}}+C_{\mathrm{w}}\right)\left[\mathrm{s}^{-1}{ }^{\circ} \mathrm{C}^{1-q}\right]$. These parameters can be determined as outlined in section 6.1 . Analysis of experimental cooling curves, according to the integrated Eq. (20), reveals that $q$ cannot be determined accurately, due to the naturally occurring scatter in the temperature data. We prefer a different approach:

The temperature vs time plot is split into a number of small temperature intervals. For each interval, we assume that the heat loss is proportional to $\Delta T$. Regression analysis of the plot, according to the logarithmic Eq. (21), yields the values for the parameter $\left(U A /\left(C_{\mathrm{w}}+M c_{\mathrm{p}}\right)\right)_{\text {local }}$. These values correspond to the logarithmic mean temperature in the adopted interval. When all the intervals have been evaluated, a correlation between the heat transfer coefficient and $\Delta T$ can be found by regression analysis.

This method is applied to the Dewar vessel, used for the supercritical experiments. Cooling of some liquids in a number of different packages is also examined. Table 6 gives a survey of the cooling experiments.

Table 6 demonstrates that, even on a small scale, the combined effect of natural convection and possibly other parameters which are slightly affected by temperature leads to a deviation from the idealized first order heat transfer. The exponent $q$ tends to increase slightly with increasing size which is in agreement with literature. We conclude that, even on a small scale, natural convection does play a role.

Fig. 12 presents the cooling curve of $400 \mathrm{~g}$ of water in a Dewar flask of $500 \mathrm{ml}$, used for the supercritical experiments. Constant ambient temperature was $19.6{ }^{\circ} \mathrm{C}$, and the initial water temperature $66.7^{\circ} \mathrm{C}$.

Regression results of the cooling curve by Eq. (20), in order to obtain the value of $q$ directly, are given in Table 7 .

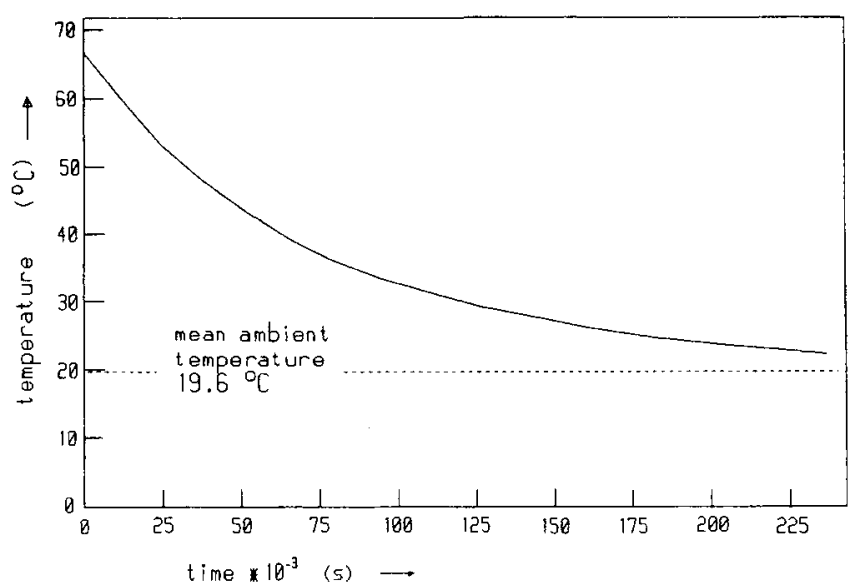

Fig. 12. Temperature as function of time for $400 \mathrm{~g}$ water in $500 \mathrm{ml}$ Dewar vessel used for supercritical experiments.

Table 7. Analysis of cooling curve of $400 \mathrm{~g}$ water, in a $500 \mathrm{ml}$ Dewar vessel, by Eq. (20).

\begin{tabular}{|c|c|c|}
\hline $\begin{array}{l}\text { Test value } \\
\text { of } q\end{array}$ & $\begin{array}{l}\text { Regression equation } \\
\text { for temperature range } \\
66.7^{\circ} \mathrm{C} \text { to } 31.1^{\circ} \mathrm{C}\end{array}$ & $\begin{array}{l}\text { Regression equation } \\
\text { for temperature range } \\
30.8^{\circ} \mathrm{C} \text { to } 23.2^{\circ} \mathrm{C}\end{array}$ \\
\hline $1.01^{\mathrm{a})}$ & $y=-0.0403-0.04537 t$ & $y=-0.00099-0.0407 t$ \\
\hline 1.10 & $y=-0.0193-0.0342 t$ & $y=+0.0088-0.0345 t$ \\
\hline 1.20 & $y=-0.00523-0.0251 t$ & $y=-0.0146-0.0288 t$ \\
\hline 1.25 & $y=-0.00085-0.021 t$ & not determined \\
\hline
\end{tabular}

a) $q=1.01$ is close to Newtonian cooling behaviour. $q=1$ would give an indeterminate result in Eq. (20).

The regression analysis according to Eq. (20), which looks so attractive if applied to calculated data, is rather difficult to use for the experimental cooling examples given in Table 6. It is not absolutely clear from Table 7 as to what is the best value for the exponent $q$. Therefore, we favour the indirect analysis in which $U A /\left(C_{\mathrm{w}}+M c_{\mathrm{p}}\right)_{\text {local }}$ is derived as a function of $\Delta T$. Application of this method yields the data given in Table 8 .

These data are analyzed according to the regression function $U A /\left(C_{\mathrm{w}}+M c_{\mathrm{p}}\right)_{\text {local }}=\Delta T_{\mathrm{ln}}^{q-1}$, so that the intercept on the

Table 6. Evaluation of cooling experiments.

\begin{tabular}{lll}
\hline $\begin{array}{l}\text { Experimental } \\
\text { cooling } \\
\text { condition }\end{array}$ & $\begin{array}{l}\text { Range of temp. } \\
\text { differences } \\
\text { in experiment }[\mathrm{K}]\end{array}$ & $\begin{array}{l}\text { Slope of } \\
\text { curve } \\
s^{-1} \Delta T^{1-q}\end{array}$ \\
\hline $\begin{array}{l}400 \mathrm{ml} \text { isododecane } \\
\text { in a } 500 \mathrm{ml} \text { Dewar vessel }\end{array}$ & 1.4 to 32 & $1.09 \times 10^{-5}$ \\
$400 \mathrm{ml}$ water in a \\
$500 \mathrm{ml}$ Dewar vessel \\
$\begin{array}{l}101 \text { isododecane in } \\
101 \mathrm{PE}-\text { bottle }\end{array}$
\end{tabular}


$y$-axis tends to zero. This yields $(U A)^{\prime} /\left(C_{\mathrm{w}}+M c_{\mathrm{p}}\right)=$ $0.70 \times 10^{-5} \mathrm{~s}^{-1} \Delta T^{q-1}$ and $q=1.2$. The data of Table 6 were similarly obtained. Table 8 shows that, at small temperature gradients, the influence of fluctuating ambient temperature (because critical experiments are usually carried out in sturdy and rather simple equipment with on/off controllers) becomes significant and the results become unreliable.

Table 8. Characterization of cooling of $400 \mathrm{~g}$ water in a $500 \mathrm{ml}$ Dewar vessel. Cold room temperature: $19.6^{\circ} \mathrm{C}$ and initial temperature: $66.7^{\circ} \mathrm{C}$.

\begin{tabular}{llll}
\hline $\begin{array}{l}\text { Temperature interval } \\
\text { from .... to ... }\end{array}$ & $\Delta T_{\mathrm{ln}}$ & $\begin{array}{l}\text { Value of } \\
\mathrm{UAq}\end{array}$ & $\begin{array}{l}\text { Regression } \\
\text { coefficient }\end{array}$ \\
{$\left[{ }^{\circ} \mathrm{C}\right]$} & {$\left[{ }^{\circ} \mathrm{C}\right]$} & $\begin{array}{l}\frac{\left(\mathrm{C}_{\mathrm{w}}+\mathrm{Mc}_{\mathrm{p}}\right)_{\text {local }}}{\left[\mathrm{h}^{-1}\right]} \\
\end{array}$ & $r$ \\
\hline $66.7 \ldots .53 .6$ & 40.195 & 0.0543 & 0.9999 \\
$51.9 \ldots .43 .7$ & 28.000 & 0.0487 & 0.998 \\
$42.5 \ldots . .36 .7$ & 19.85 & 0.0468 & 0.997 \\
$36.4 \ldots . .32 .6$ & 14.82 & 0.04198 & 0.9996 \\
$31.5 \ldots .29 .0$ & 10.60 & 0.0390 & 0.997 \\
$28.7 \ldots .26 .8$ & 8.11 & 0.0406 & 0.998 \\
\hline
\end{tabular}

\subsubsection{Supercritical Experiments in a Dewar Vessel}

The critical condition for the above-mentioned peroxide could be calculated from Eqs (15) and (24), once the characteristics of the applied Dewar vessel were known. These were established with the particular peroxide in a low-temperature range, where self-heating is irrelevant, and found to be $q=1.2$ and $(U A)^{\prime} /\left(M c_{\mathrm{p}}+C_{\mathrm{w}}\right)=1.32 \times 10^{-5} \mathrm{~s}^{-1}{ }^{\circ} \mathrm{C}^{-0.2}$ so that $\delta_{\mathrm{cr}}=$ 1.295 for $m=2.5$, which is an approximative value for this shape of vessel. Further, the adiabatic temperature rise $\Delta T_{\mathrm{ad}}$ is $231{ }^{\circ} \mathrm{C}$. In the calculation of $\Delta T_{\mathrm{ad}}$, the specific heat capacity of the Dewar vessel with contents must be adopted since the vessel acts as a heat sink, similar to the phlegmatizing agent isododecane. Heat capacity of the Dewar vessel is estimated from the temperature drop of hot water, suddenly poured into the cold vessel, as $C_{\mathrm{w}}=116 \mathrm{~J} / \mathrm{K}$. Hence, the effective specific heat capacity of the Dewar vessel and its contents is $\left(M c_{\mathrm{p}}+C_{\mathrm{w}}\right) / M=2531 \mathrm{~J} / \mathrm{K} \mathrm{kg}$ instead of $2176 \mathrm{~J} / \mathrm{K} \mathrm{kg}$ and $\Delta T_{\mathrm{ad}}$, corrected for the Dewar vessel's heat capacity, is $\Delta T_{\mathrm{ad}}=$ $269 \times 2176 / 2531=231 \mathrm{~K}$.

The critical ambient temperature $T_{0, \mathrm{cr}}$ follows from the definition of $\delta_{\mathrm{cr}}$

$\delta_{\mathrm{cr}}=\frac{E}{R T_{\mathrm{o}, \mathrm{cr}}} \frac{\varrho r}{U_{0}} C \exp \left(-\frac{E}{R T_{\mathrm{o}, \mathrm{cr}}}\right)$

with $\frac{\varrho r}{U_{0}}=\frac{\varrho}{U_{0}} \frac{m V}{A}=\frac{m}{U_{0}} \frac{M}{A}=\frac{m}{c_{\mathrm{p}}\left(\beta T_{0}\right)^{q-1}} \frac{M c_{\mathrm{p}}}{U^{\prime} A}$

Insertion of all known data yields $\varrho r / U_{0}=50.7 \mathrm{~kg} \mathrm{~K} / \mathrm{W}$ and solution of the critical condition for $\delta_{\mathrm{cr}}=1.295$ results in $T_{0, \mathrm{cr}}$ $=301.4 \mathrm{~K}=28.4^{\circ} \mathrm{C}$.

Hence, the peroxide in this Dewar vessel will undergo a runaway reaction which cannot be arrested by cooling if am-

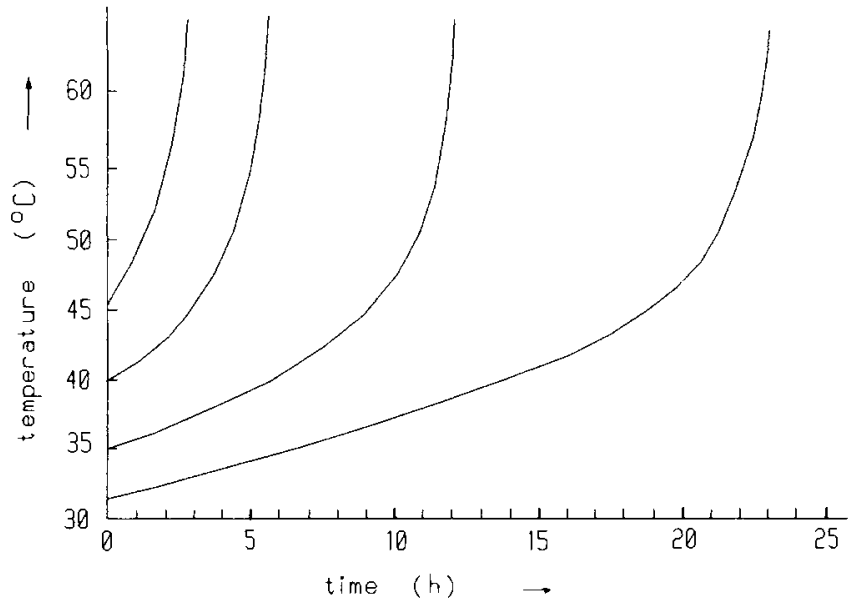

Fig. 13. Temperature runaways of $t$-butyl peroxypivalate. 40 mass- $\%$ in isododecane; supercritical conditions in a $500 \mathrm{ml}$ Dewar vessel.

bient temperature exceeds $28.4^{\circ} \mathrm{C}$. A series of supercritical experiments were performed by rapidly heating the peroxide solution to the desired initial temperature and placing it in preheated surroundings. Fig. 13 presents the temperature profiles of the supercritical experiments, and Table 9 summarizes the evaluation data.

The experimental data $t_{\text {expl }} / t_{\text {ad }}$ are shown in the adapted $\tau-\mathrm{d}$ diagram, Fig. 10. It is seen that these points lie on the "all corrections" line.

The question "does incorporation of natural convection effects alter our safety assessment of a given cooling situation, compared to using a less sophisticated method which neglects this effect ?" can now be answered. The analysis of the cooling experiments, given in Table 6, shows that natural convection ef fects do indeed play a role and lead to a certain range of parameter values $(U A)^{\prime} /\left(M c_{\mathrm{p}}+C_{\mathrm{w}}\right)$, which, in turn, are associated with a range of critical ambient temperatures $T_{0, \mathrm{cr}}$ for a particular self-heating problem. Table 10 shows the outcome of comparative calculations of $T_{0, \mathrm{cr}}$.

A storage vessel, with the same cooling behaviour as that in the hypothetical situation of Table 2 , is considered with $q=$ $1.333 .$. , and $(U A) / M c_{\mathrm{p}}=0.03 \mathrm{~h}^{-1} \mathrm{~K}^{-1 / 3}$; the heat capacity of a large vessel can be neglected compared to its contents. The self-heating substance is again $t$-butyl peroxy pivalate $40 \mathrm{wt}-\%$ in isododecane, with the characteristic parameters $\Delta T_{\mathrm{ad}}, c_{\mathrm{p}}, Q_{\infty}$ and $E / R$ as given.

Table 9. Evaluation of supercritical experiments.

\begin{tabular}{lllll}
\hline $\begin{array}{l}\text { Initial temp. } \\
\text { of peroxide, } \\
\text { equal to oven } \\
\text { temperature }\end{array}$ & $\begin{array}{l}\text { Calculated } \delta \\
\text { value } \\
{\left[{ }^{\circ} \mathrm{C}\right]}\end{array}$ & $\begin{array}{l}\text { Calculated } \\
\text { induction time } \\
t_{\text {ad }} \text {, from } \\
\text { Eq. }(18) \\
{[\mathrm{h}]}\end{array}$ & $\begin{array}{l}\text { Calculated } \\
\text { runaway time }\end{array}$ & $\begin{array}{l}\text { Experimental } \\
\text { runaway } \\
\text { time }\end{array}$ \\
\hline 31.7 & 2.21 & 17.2 & 26.8 & 23.4 \\
35.2 & 3.61 & 10.55 & 13.4 & 12.3 \\
40.0 & 6.94 & 5.5 & 6.2 & 6.0 \\
45.1 & 13.6 & 2.8 & 3.0 & 2.7 \\
\hline
\end{tabular}


Table 10. Calculation of critical ambient temperature in a self-heating case, where cooling by natural convection is important. Cooling curve for the vessel is the same as in Table 2. Properties of peroxide: $\Delta T_{\mathrm{ad}}=269 \mathrm{~K}$. $c_{\mathrm{p}}=2176 \mathrm{~J} / \mathrm{kgK}, Q_{\infty}=1.18 \times 10^{19} \mathrm{~W} / \mathrm{kg}$ and $E / R=13753 \mathrm{~K}$.

\begin{tabular}{llll}
\hline Type of analysis & $\begin{array}{l}\text { Value of } \\
(\delta \mathrm{e} / m)_{\mathrm{cr}}\end{array}$ & $\begin{array}{l}\text { Value of } \\
\mathrm{\varrho} / U_{0} \\
\text { for } m=\mathrm{e}\end{array}$ & $\begin{array}{l}\text { Value of } T_{0, \mathrm{cr}}, \text { first } \\
\text { trial } T_{0, \mathrm{cr}} \text { is } 299 \mathrm{~K} \\
{[\mathrm{~K}]}\end{array}$ \\
\hline $\begin{array}{l}\text { non-Newtonian, } \\
\text { full } T \text {-range }\end{array}$ & 1.4381 & 80.314 & 298.5 \\
$\begin{array}{l}\text { Newtonian. } \\
\text { range } 60 \ldots 53{ }^{\circ} \mathrm{C}\end{array}$ & 1.294 & 45.29 & 301.8 \\
$\begin{array}{l}\text { Newtonian range } \\
60 \ldots 40{ }^{\circ} \mathrm{C}\end{array}$ & 1.294 & 49.75 & 301.1 \\
$\begin{array}{l}\text { Newtonian } \\
\text { range } 47 \ldots 30^{\circ} \mathrm{C}\end{array}$ & 1.294 & 59.96 & 299.8 \\
$\begin{array}{l}\text { Newtonian, } \\
\text { range } 29 \ldots 25{ }^{\circ} \mathrm{C}\end{array}$ & 1.294 & 76.61 & 298.2 \\
\hline
\end{tabular}

\section{Conclusions}

The induction time to runaway under supercritical conditions for a reacting batch, exemplified by adopting excessively high cooling temperature for cooled storage of a self-heating substance, can be accurately calculated with a generalized equation. This equation uses, on the one hand, the distance to the critical condition, which can be derived from thermal stability properties of the self-heating substance and the heat transfer coefficient and, on the other hand, the adiabatic induction time to runaway, which is determined solely by the physical properties of this substance. Thermal properties can be measured by a number of established techniques, preferably in a temperature range where a thermal runaway may also take place. Storage vessels are usually jacketed and unstirred because agitation drastically reduces the time to runaway in case of accidental cooling failure. The heat transfer coefficient can be best derived by analyzing the cooling behaviour of the self-heating substance at a safe, low temperature. Cooling is often assumed to be Newtonian, but natural convection within the vessel results in the heat flow rate becoming a weak exponential function of the temperature difference. We found that this occurs even in laboratory experiments. Newtonian analysis as opposed to the correct method may yield a higher critical ambient temperature than the true value, but the difference is quite small, approximately $3 \mathrm{~K}$. The difference becomes very small when the temperature gradients in the determination of the cooling curve are kept small. Performance of the rigorous, rather cumbersome, calculation of the critical condition is recommended if the actual operating conditions for the storage vessel are supercritical and, as a consequence, the induction time is finite. If only a quick estimate is required whether the cooling conditions are subcritical or supercritical, we recommend adoption of the classical approach by Semenov.

\section{Appendix 1: Analytical Calculation for the Simplest Case Induction Times}

The derivation starts with Eq. (3), with $\theta_{\text {expl }}=\infty$ as the upper limit for the integration. The integrand, being a quotient, can be expanded algebraically according to:

$$
\begin{gathered}
\begin{aligned}
\tau_{\text {expl }}= & \int_{0}^{\infty}\left[\frac{1}{\delta} \exp \left(\frac{\theta}{1+\beta \theta}\right)+\frac{m \theta}{\delta^{2}} \exp \left(-\frac{2 \theta}{1+\beta \theta}\right)+\frac{m^{2} \theta^{2}}{\delta^{3}} \times\right. \\
& \left.\times \exp \left(-\frac{3 \theta}{1+\beta \theta}\right)+\ldots\right] \mathrm{d} \theta \\
\text { or: } \tau_{\text {expl }}= & \int_{0}^{\infty} \frac{1}{\delta}\left[\sum_{i=1}^{\infty}(m \theta / \delta)^{n-1} \exp \left(-\frac{n \theta}{1+\beta \theta}\right)\right] \mathrm{d} \theta .(\mathrm{a} 1-2)
\end{aligned}
\end{gathered}
$$

The terms in Eq. (a $1-2)$ can be found by partial integration carried out in such a way that the exponent $(n-1)$ on $(m \theta / \delta)$ is reduced stepwise:

$$
\begin{array}{rlr}
\tau_{\text {expl }}= & I_{1}+\ldots I_{n}+I_{n+1}+\ldots \text { where } I_{n}=\frac{1}{\delta} \int_{0}^{\infty}(m \theta / \delta)^{n-1} \times \\
& \times \exp \left(-\frac{n \theta}{1+\beta \theta}\right) \mathrm{d} \theta & (\mathrm{a} 1-3)
\end{array}
$$

The primitive function of $\exp (-n \theta /(1+\beta \theta))$ is not known and no approximation covering all values of $n$ and the full range of $\theta$ from 0 to $\infty$ could be found. Only the special case of $\beta=0$ can be solved analytically. We proceed with Eq. (al -3 ) by applying the partial integration principle, taking into account that:

$\left.\frac{1}{n} \theta^{n-p} \exp (-n \theta)\right|_{0} ^{\infty}=0$ for $p<n$ and any value of $\theta$.

Evaluation of Eq. (a1 - 3) yields for the first partial integration:

$I_{\mathrm{n}}=(1 / \delta)(m / \delta)^{n-1} \frac{n-1}{n} \int_{0}^{\infty} \theta^{n-2} \exp (-n \theta) \mathrm{d} \theta$

Further reductions of the exponent on $\theta$, until it becomes zero, yield:

$$
\begin{aligned}
I_{\mathrm{n}}= & (1 / \delta)(m / \delta)^{n-1} \frac{n-1}{n} \frac{n-2}{n} \ldots \frac{1}{n} \frac{1}{n}=(1 / \delta)(m / \delta)^{n-1} \times \\
& \times \frac{(n-1) !}{n^{n}} .
\end{aligned}
$$

Hence:

$\tau_{\text {exp } 1} \delta=\left|1+(m / \delta) \frac{1 !}{2^{2}}+(m / \delta)^{2} \frac{2 !}{3^{3}}+\ldots\right| \cdot \quad(\mathrm{a} 1-4)$

Transposition yields Eq. (4), as Se $=(\delta / m)$ and $\tau_{\text {expl }} \delta=\left(t / t_{\text {ad }}\right)$.

\section{Critical Condition}

In the series, given by Eq. (al - 4), the individual terms can be calculated by a recurrent correlation, starting from the first term, i.e. $\operatorname{term}(1)=I_{1}=1$ :

$\operatorname{term}(\mathrm{i})=I_{\mathrm{i}}=I_{\mathrm{i}-1} \mathrm{e} / a((i-1) / \mathrm{i})^{i}$ where $a=\mathrm{e} / m^{\delta}=\mathrm{Se} / \mathrm{Se} \mathrm{er}$.

For large values of $i$ the following correlation is valid:

$((i-1) / \mathrm{i})^{i}=\mathrm{e}^{-1}$ 
Hence, the higher terms are calculated according to:

$I_{\mathrm{i}} \approx I_{\mathrm{i}-\mathrm{l}} / a$

The sum $\sum_{i=1}^{\infty} I_{i}$ is known to be convergent only if $a>1$. Therefore, the critical condition is $\delta_{\mathrm{cr}}=(\mathrm{m} / \mathrm{e})$, or $\mathrm{Se}_{\mathrm{cr}}=1 / \mathrm{e}$.

\section{Appendix 2: Mathematical Treatment of Sharp Tempera- ture Increases and Criticality}

Criticality calculations must be carried out with great precision if the maximum subcritical temperature excess $\theta_{\max }$ is to be found. For example, the following results are obtained in the vicinity of $\delta_{\mathrm{cr}}$ for $\Delta T_{\mathrm{ad}}=400 \mathrm{~K}$ and $\beta=0.03$ :

$(\delta \mathrm{e} / m)=1.2910$ is subcritical, and $\theta_{\max }=2.21$;

$(\delta \mathrm{e} / m)=1.2915$ is subcritical, and $\theta_{\max }=3.58$

$(\delta \mathrm{e} / m)=1.291508$ is supercritical, because $\theta_{\max }>5$.

The integration step $h$ for the numerical integration must decrease sharply on reaching higher values of $\theta$, for example:

if $0<\theta<1.8$, select $h=h_{0}, h_{0}=0.01 / \delta$ or smaller is suggested;

if $1.8<\theta<2.8$, select $h=h_{0} / 4$;

if $2.8<\theta<4$, select $h=h_{0} / 15$;

if $\theta>4$, select $h=h_{0} / 100$.

These values were optimized in an empirical way.

The basis is the very sharp temperature rise close to the explosion point. For numerical evaluation of the temperature profile in the adiabatic case, the following approximation, based on the assumption of $\beta \theta$ being negligible compared to unity, is essential ("the Frank-Kamenetskii substitution"):

$\exp \left(-\frac{E}{R T}\right) \approx \exp \left(-\frac{E}{R T_{0}}\right) \exp \left(-\frac{E}{R T_{0}^{2}}\left(T-T_{0}\right)\right)$

It is now possible to integrate the heat balance

$c_{\mathrm{p}} \frac{\mathrm{d} T}{\mathrm{~d} t}=Q_{\infty} \exp \left(-\frac{E}{R T}\right)$.

This eventually yields:

$\left(T-T_{0}\right) \frac{E}{R T_{0}^{2}}=\theta=\ln \frac{1}{1-t / t_{\mathrm{ad}}}$

where $t_{\mathrm{ad}}$ is the adiabatic induction time according to Eq. (4b).

The mathematical form of Eq. (a2-1) makes it obvious that, in the initial period, the temperature rise is approximately linear but, on reaching $t \approx t_{\mathrm{ad}}$, the temperature increases asymptotically to infinity.

\section{Appendix 3: Conversion of Thermal Explosion Parameters to their Chemical Reaction Engineering Equivalents}

Thermal explosion science applies a number of different parameters, based on kg's rather than moles and on heat production rate rather than chemical conversion rate. The reason is that the starting materials are often quite complex mixtures, or the products are either difficult to define chemically or are unimportant. The conversion equations are derivable as follows.

Assume that the batch reaction $\nu_{\mathrm{A}} \mathrm{A} \rightarrow \nu_{\mathrm{c}} \mathrm{C}$ takes place in a volume $V$, and the reaction enthalpy per unit mass of $A$ is $\Delta H_{\mathrm{r}, \mathrm{w}}$. The equivalent molar heat of reaction, with the usual dimension of heat per $\mathrm{kmol}$ of product $\mathrm{C}$, is $\Delta H_{\mathrm{r}}$. The initial mass fraction of $\mathrm{A}$ is $w_{\mathrm{A} 0}$, and its initial molar concentration is $c_{\mathrm{A} 0}$. The average density of the reacting system is $\varrho$. The amount of heat released after total conversion of $\mathrm{A}$ is:

$\varrho^{V w_{\mathrm{A} 0} \Delta H_{\mathrm{r}, \mathrm{w}}}=V c_{\mathrm{A} 0} \nu_{\mathrm{A}} \Delta H_{\mathrm{r}} / \nu_{\mathrm{c}}$

Hence:

$\Delta H_{\mathrm{r}}=\frac{\varrho w_{\mathrm{A} 0} \Delta H_{\mathrm{r}, \mathrm{w}}}{c_{\mathrm{A} 0}} \frac{\nu_{\mathrm{A}}}{\nu_{\mathrm{c}}}$

The heat production factor, being the heat production rate at infinitely high temperature and zero conversion, is:

$Q_{\infty}=k_{1,1 \text { at } T=\infty} \Delta H_{\mathrm{r}} c_{\mathrm{A} 0} c_{\mathrm{B} 0} / \varrho$ for a second order reaction

or

$Q_{\infty}=k_{1 \text { at } T=\infty} \Delta H_{\mathrm{r}} c_{\mathrm{A} 0} / \varrho$ for a first order reaction.

\section{Acknowledgements}

These investigations were supported by Akzo Chemicals, bv., Research Centre Deventer, The Netherlands. We are grateful to Richard Bollen, who performed the experiments and to Jan de Groot for the scientific back-up.

Received: May 21, 1990 [CET 302]

\section{Symbols used}

$\begin{array}{ll}A & {\left[\mathrm{~m}^{2}\right]} \\ A & \\ B & \\ c & {\left[\mathrm{kmol} / \mathrm{m}^{3}\right]} \\ c_{\mathrm{p}} & {[\mathrm{J} / \mathrm{kg} \mathrm{K}]} \\ C_{\mathrm{w}} & {[\mathrm{J} / \mathrm{K}]} \\ E & {[\mathrm{~J} / \mathrm{kmol}]}\end{array}$

heat transfer area adjustable parameter in Eq. (5) adjustable parameter in Eq. (5) molar concentration specific heat capacity at constant pressure heat capacity of (Dewar) vessel energy of activation

$\begin{array}{ll}\mathrm{Gr} & \\ g & {\left[\mathrm{~m} / \mathrm{s}^{2}\right]} \\ \Delta H_{\mathrm{r}, W} & {[\mathrm{~J} / \mathrm{kg}]}\end{array}$
enthalpy change per unit mass 


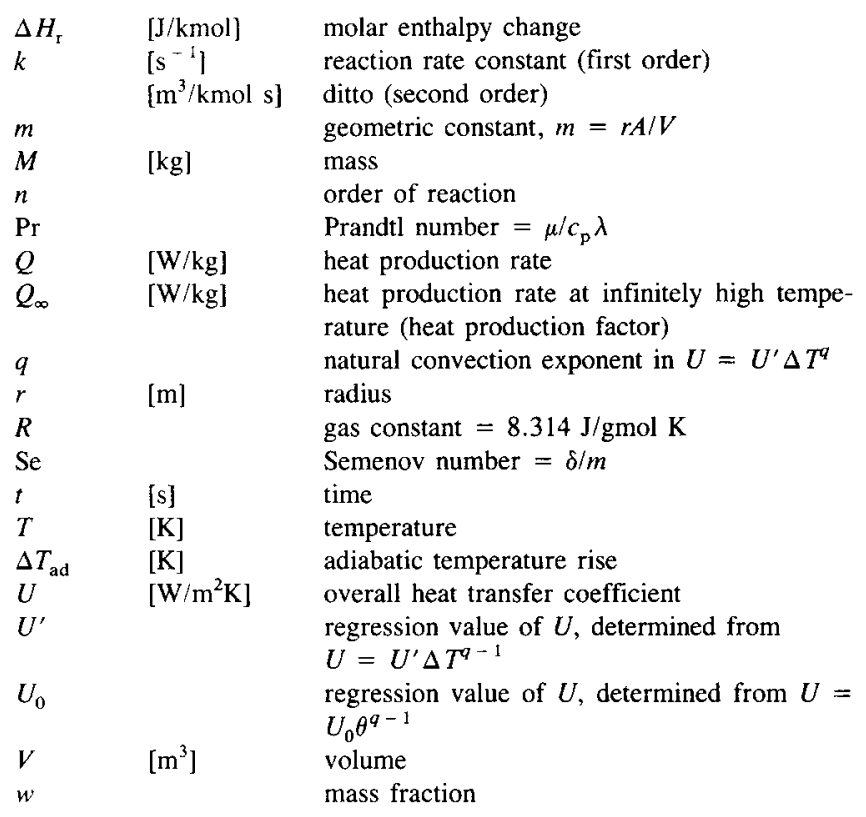

\section{Dimensionless Parameters and Greek Symbols}

$\theta$

$\beta$

$\tau$

$\zeta$

$\nu \quad\left[\mathrm{m}^{2} / \mathrm{s}\right]$

$\nu_{\mathrm{A}}, \nu_{\mathrm{B}} \ldots$

$\mu \quad\left[\mathrm{Ns} / \mathrm{m}^{2}\right]$

$\delta$

$\lambda \quad[\mathrm{W} / \mathrm{mK}]$ dimensionless temperature increase, $\theta=$ $E\left(T-T_{0}\right) / R T_{0}{ }^{2}$

reciprocal dimensionless activation energy, $\beta=R T_{0} / E$

dimensionless time, $\tau=U t / \mathrm{Q} c_{\mathrm{p}} \mathrm{r}$

conversion

kinematic viscosity

stoichiometric coefficients

viscosity

$\delta=\frac{E}{R T_{0}^{2}} \frac{\varrho r}{U} Q_{\infty} \exp \left(-\frac{E}{R T_{0}}\right)=$ dimensionless heat production rate thermal conductivity

$\begin{array}{lll}\gamma_{\mathrm{H}} & \gamma_{\mathrm{H}}=\frac{R T_{0}^{2}}{E \Delta T_{\mathrm{ad}}} & \begin{array}{l}\text { correction for reactant } \\ \text { consumption }\end{array} \\ \varrho & {\left[\mathrm{kg} / \mathrm{m}^{3}\right]} & \text { density }\end{array}$

\section{Subscripts}

ad adiabatic

o reference or initial value

cr critical

expl explosion

wall at wall (in the Grashof number $\mathrm{Gr}$ )

$\infty \quad$ at infinitely high temperature or distance

$1 / 2$ in: thermal half-life $t_{1 / 2}$

\section{References}

[1] Merzhanov, A.G., Abramov, V.G., Propellants Explos. 6 (1981) pp. $130-148$

[2] Bowes, P.C., Self-heating: evaluation and controlling the hazards, Elsevier, Amsterdam 1984.

[3] Akzo Chemicals, brochure Noury Initiators Delivery Programme for the Thermoplastics Industry, Amersfoort, The Netherlands, 1989.

[4] Gray, P., Lee, P.R., Thermal Explosion Theory, in: Oxidation and Combustion Reviews, Vol 2. (C.F. Tipper, Ed.), Elsevier, Amsterdam 1967.

[5] Gray, B.F., Sherrington, M.E., Combust. Flame 19 (1972) pp. $435-444$ and $445-448$.

[6] Beek, W.J., Muttzall, K.M.K., Transport Phenomena, John Wiley \& Sons, Chichester, UK, 1972.

[7] Perry, R.H., Chilton, C.H., Chemical Engineers' Handbook, McGraw-Hill, New York 1973.

[8] Moise, A., Pritchard, H.O., Can. J. Chem. 60 (1982) pp. 165-167.

[9] Merzhanov, A.G., Shtessel, E.A., Dokl. Akad. Nauk SSSR 194 (1970) No. 1, pp. 136-138.

[10] Vasseur, P., Robillard, L., Waerme-Stoffuebertrag. 16 (1982) pp. $199-207$.

[11] UNO book on Transport of Dangerous Goods, Tests and Criteria, United Nations, New York 1988.

[12] van de Putte, T., Groothuizen, Th.M., TNO-nieuws, (special issue by TNO, P.O.Box 45, Rijswijk, The Netherlands) 1971, pp. 48-55.

[13] Hordijk, A.C., Verhoeff, J., de Groot, J.J., Thermochim. Acta 43 (1981) No. 9, pp. $75-90$. 